\title{
The Road to Grandma's House: The Daily Experiences of Economically \\ Disadvantaged Elderly Women in Rural and Urban Ottawa
}

\section{By}

Julie S. Lalonde, B.A. (Hon.)

\begin{abstract}
A thesis submitted to the Faculty of Graduate and Postdoctoral Affairs in partial fulfillment of the requirements for the degree of
\end{abstract}

\author{
Master of Arts \\ School of Canadian Studies
}

\author{
Carleton University \\ Ottawa, Canada \\ (C) 2013
}




\begin{abstract}
Elders are the fastest growing segment of the Canadian population; yet, little is written about their lives. Using an intersectional analysis, I conducted qualitative interviews with economically disadvantaged elderly women in the Ottawa area to try and uncover the daily experiences of being a woman who is both elderly and living in poverty. My research argues that elderly women are invisible in Canada and that the consequence of this erasure is that we fail to recognize the ways in which economically disadvantaged elderly women are incredibly resilient and resourceful. However, I caution against simply praising their resiliency. Instead, I advise a critical examination of the systemic barriers that force elderly women to work so hard to survive.
\end{abstract}

Keywords: intersectionality, feminist gerontology, poverty, elderly, rural, urban 


\section{Acknowledgements}

This thesis easily could have been titled "The road to Julie's thesis defense". It has been a long and arduous journey that would not have been possible without the unwavering support of my supervisor, Dr. L. Pauline Rankin. She believed in me when few others did and I am forever grateful for her guidance, encouragement and tough love. We did it, Pauline!

Thank you to the team of doctors and specialists who literally kept me going. My health has failed me many times but thankfully, Medicare is still there to catch me when I fall.

Thank you to my amazing partner Jeff who has been my sounding board, Sherpa and editor for 8 years. I also appreciate your vegan spaghetti and meatballs.

I am the first person in my family to go to university and this would not have been possible without the sheer will and dedication of my parents. When every attempt was made to throw me off course, my parents told me to remember why I was doing this. The occasional cheque didn't hurt either.

I want to dedicate my research to my own grandmothers. My maternal grandmother Lilliane Tellier who fought for the rights of people with disabilities and my paternal grandmother Lillian Bellmore who spends her days visiting "old folks' homes."

I stand on the shoulders of giants. 


\section{Table of Contents}

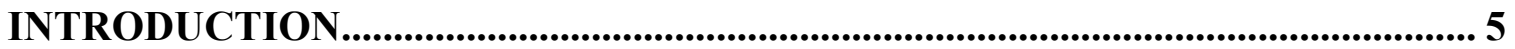

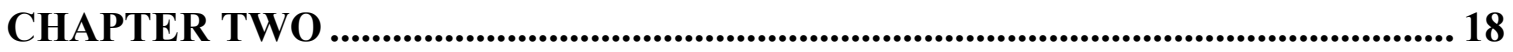

THEORETICAL FRAMEWORK .................................................................. 18

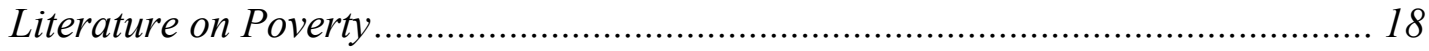

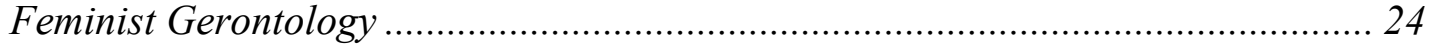

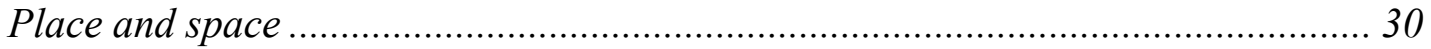

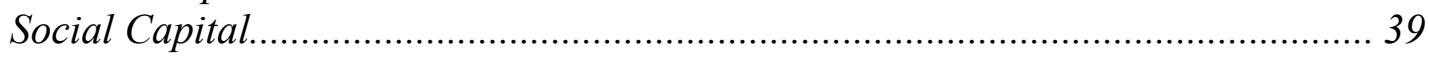

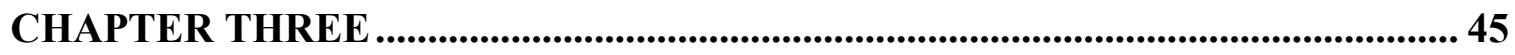

METHODOLOGY AND METHODS ....................................................................... 45

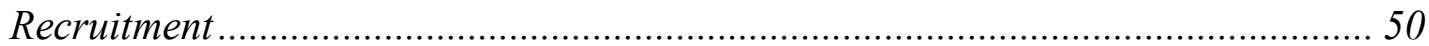

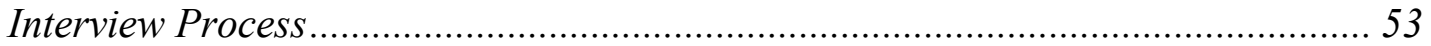

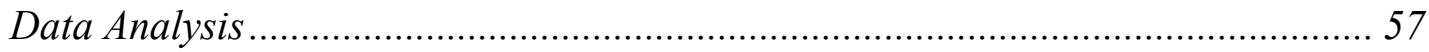

CHAPTER FOUR : “LIFE SURE HAS ITS CHALLENGES, BUT SOMEHOW WE GET THROUGH IT": RESOURCEFULNESS AND RESILIENCE ............... 58

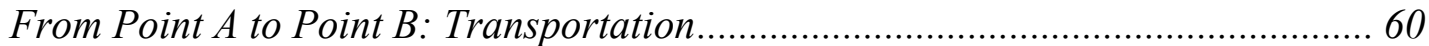

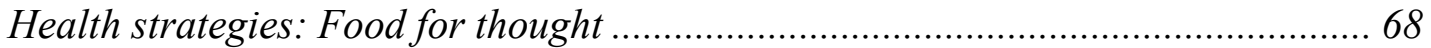

"I get by with a little help from my friends": Care ............................................. 72

CHAPTER FIVE: "SO TO SAY I HAVE AN EASY TIME? I DON'T": THE

LIMITATIONS OF "RESILIENCE" ....................................................................... 80

CHAPTER SIX: CONCLUSION ........................................................................ 92

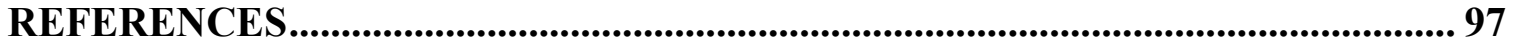

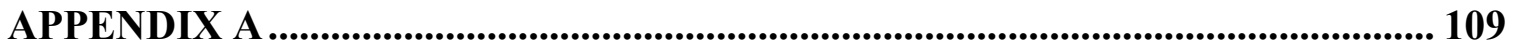

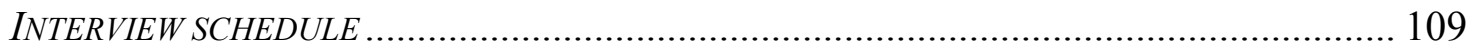

APPENDIX B ........................................................................................................................ 111

EXCERPT FROM A NOTE THAT LORRAINE WROTE TO ME AFTER OUR INITIAL INTERVIEW ..... 111 


\section{$\underline{\text { Introduction }}$}

It is a unique time to be engaged in research focused on aging as elders are the fastest-growing segment of the Canadian population with the "dependency ratio - which shows the number of people over the age of 65 , compared with those younger than $65-$ [rising] from about 20 per cent today to about 40 per cent over the next two decades" (Priest, 2011: B3). With the aging of so-called baby boomers, the elderly have been written about extensively (Aronson, 1992, 1994 and 2000; Calasanti, Slevin and King, 2006; Curry, 2012; Kelly, 2008). ${ }^{1}$ Unfortunately, much of the current literature on the elderly produces what I term "elder hysteria" that privileges attention to the trials of the "sandwich generation" caring for children and aging parents, the inevitable costs of aging on the health care system, the strain on the pension system, controversial mandatory retirement policies and other similar issues that frame our discussions of the elderly as cause for much concern (Calasanti, Slevin and King, 2006; Simpson, 2012; Curry, 2012; Kelahear, 2012).

The overwhelming majority of mainstream discussions of the elderly revolve around the economic implications of an aging population on the public purse:

Depictions of old people and the health care system in the media and popular discussion mirror policy makers' and politicians' concerns with government expenditure, often in tones of alarm and apprehension about the growing 'burden' of the elderly population. (Aronson, 1994: 20)

Public debate tends to position the elderly as disabled and in poor health; the elderly are depicted most frequently as medical patients rather than fully-rounded citizens and

\footnotetext{
${ }^{1}$ This thesis employs the Indigenous term "elderly" versus "senior" to denote a term of respect. My choice of terminology is explained further in Chapter Three.
} 
community members. While there is a lively discourse about aging and the elderly, rarely, however, do we talk to or with the elderly. It is ironic that in contemporary debates about elderly people, health and social services we hear little from elderly people themselves (Aronson, 2000: 53). More specifically, by framing our discussions most frequently in quantitative (and almost universally negative) terms, we perpetuate the idea that Canada's elderly are burdens on society. In turn, the elderly become scapegoats for economic crises and poor financial planning by governments resulting in collective anger at elderly people for "mooching" off a system that "we" built (Townson, 2006).

There is a persistent failure to acknowledge the elderly as a vibrant demographic integral to the fabric of society. Rather than being recognized as long-time participants in the economy and the social fabric of Canada, the elderly are often relegated to the margins of society with minimal visibility in the mainstream. It is perhaps universal that people slow down physically as they age, but within mainstream North American culture, people lose value as they age. By contrast, in many Indigenous cultures, for example, wisdom is deemed to increase with age and the elderly, in fact, enjoy a revered status (Richmond, 2007).

There are many theories to explain the mainstream devaluing of elderly people in North America, including the idea that sexism is a significant factor. Gerontologists Peter Leonard and Barbara Nichols argue that the elderly are devalued in large part because women constitute the majority of all elderly people. Like "pink ghettos" in the job market, once women dominate a category, it becomes less prestigious. As they argue: "Ageism and sexism thus subtly complement each other" (1994: 13). Feminist gerontologists argue that the absence of elderly women's voices in research on the elderly 
means that such research fails to recognize the reality of the unique power structure of age relations: "Unlike other hierarchies, in which the privileged rarely become the oppressed, we all face age oppression if we live long enough" (Calasanti, Slevin and Neal, 2006: 25).

This thesis examines the daily experiences of economically disadvantaged elderly women in rural and urban Ottawa. I argue that elderly women's voices are frequently absent from public discussions of Canada's aging population. The result is that we fail to appreciate an incredibly resilient and resourceful segment of the population. My usage of the term "resilience" is in reference to one's capacity to successfully overcome hardship and adversity (Wild, Wiles and Allen, 2013; Aubrecht, 2012; Welsh, 2012; Joseph, 2013; Earvolino-Ramirez, 2007). However, defining the women as resilient is not enough. The second part of my argument is that simply labeling elderly women as resilient erases the systemic barriers that force them to be so resilient in the first place. My research relies on 17 interviews initially conducted with the goal of uncovering the difficulty of living in poverty as an elder woman in an urban versus rural setting. My theory of a life of difficulty was confirmed as the women spoke of their hardships but their stories went further than I anticipated, demonstrating their incredible tenacity and resilience. In the course of this study, therefore, I was forced to reconsider how I had conceived of their daily lives and, as a result, to challenge my own assumptions about agency and selfdetermination. This thesis, therefore, draws on the voices of elderly women with the hope that hearing from elder women themselves can improve the conditions of their lives and the lives of Canada's future elderly. The devaluing of elderly people is not a universal trait and our placement of elderly people, and in particular elderly women, at the margins 
of Canadian society is a socially constructed power relationship born from ageist and sexist ideologies. The parallels between our treatment of the elderly and the treatment of women cannot be overestimated; my research, in fact, endeavors to make those links visible.

I approach this topic as both an academic researcher and someone with in-depth personal knowledge. Although I am not elderly myself, I had a unique relationship to my elders growing up that deeply influenced my understanding of aging and family. Both my maternal and paternal grandparents experienced a lifetime of hardship and precarious employment that left them susceptible to poverty and subsequently led to health problems. Until my teenage years, my maternal grandmother lived with her parents in a trailer outside of the town in which I was raised. At the age of 59, my grandmother collapsed at her job at a hardware store leading to the discovery that she had a brain tumour. She became disabled as a result and could no longer live in her home. My parents made the decision to renovate our home and my grandmother and greatgrandfather moved in with us. Seeing first hand how my grandparents struggled with being elderly, poor and, in my grandmother's case, disabled, fundamentally shaped my understanding of what it meant to be elderly in contemporary Canada. Even though I was surrounded by imagery of the elderly in popular culture as smiling through retirement, I witnessed a very different reality. It was not until I moved away from home to attend university that I began to question why my family's reality was not reflected elsewhere.

I became obsessed with finding out where the grandmothers were. As an undergraduate in women's studies, I was baffled by the lack of elderly women's voices in the curriculum. For example, when looking at three primary texts for introductory 
Women's and Gender Studies courses at Carleton University, only one reading in one text included discussion of elderly women (Biggs, Downe, 2005; Zinn, HondagneuSotelo and Messner, 2005; Mandell, 2001) and that reading dealt with women contending with their changing bodies through menopause (Wakewich, 2005). How is it that an entire demographic of women is absent in the one discipline that is supposed to speak to them? Where are these women? Better yet, who are these women and how do they spend their time?

I began this thesis with the express purpose of finding out how elderly women living in poverty spent their time. Although I had a unique experience of living with my grandmother and great-grandfather, I still began my research with common assumptions about the lives of Canada's elderly. I assumed that their lives were a constant battle and that I would conclude that Canada has failed its elderly by marginalizing and excluding them from the social fabric. Simultaneously, however, I was surrounded by media images of aging as "Freedom 55" with everyone living happily in retirement, taking cruises and playing golf. What I discovered is that the reality is somewhere in between and much more complex. That is, elderly women lead extraordinary lives of resilience and are active participants in their communities. As my thesis demonstrates, for women over 65 living in poverty in Canada, to exist is to resist. They continuously resist societal expectations of what it means to age successfully within an environment that systemically undervalues and overlooks them. These women are routinely ignored and one of the most obvious indicators of this is the lack of Canadian qualitative research devoted to the experiences of aging women. In a political and social climate consumed with the costs of aging on society, it is even more surprising to discover that very little has been said about 
the cost of aging from the perspective of the elderly, especially when you consider that $49 \%$ of unattached women aged 65 or older have low incomes (Townson, 2000: 1).

Although elderly women suffer a disproportionate amount of poverty as compared to other groups in Canada, they are far from a homogenous group. For this thesis, I interviewed a fairly homogenous set of participants and yet numerous categories of difference were revealed. As a group, the narrators in my thesis suffer a similar fate but their personal experiences of that poverty differ greatly. Certainly, feminists have successfully challenged the notion of gender as homogeneous to a point where the gender binary is commonly understood as simplistic and outdated; however, we continue to think of aging as a uniform category. ${ }^{2}$ Similar to discussions around the concept of "generations," there is a tension within popular culture between archaic understandings of the "elderly" as passive and idle which conflicts with the contemporary reality of an elderly population that is active and engaged (Kertzer, 1983). Although the women represented in my thesis are Canadian-born, Ottawa area-based women over 65 who selfidentify as economically disadvantaged, their experiences challenges the notion of "elderly" as a static category. In fact, many of the women explicitly stated their frustrations with having women over 65 lumped into one uniformed category. Obviously, current usage of such a broad category homogenizes definitions of "elderly." Such assumptions are particularly inaccurate and problematic in contemporary Canada where life expectancy continues to rise. ${ }^{3} \mathrm{We}$ include more and more people in the category and yet ignore the very real differences within it.

\footnotetext{
${ }^{2}$ The gender binary refers to the notion that there are only two distinct and different genders.

${ }^{3}$ Life expectancy in Canada currently stands at 83 years for women and 78 for men (Milan and Vézina, 2012).
} 
Intersectionality has been heralded by some scholars as the most important contribution of women's studies to date and is often cited as "the" feminist theory (Davis, 2008). This theoretical approach is born from critiques of existing, narrowly focused and simplistic causal theories ${ }^{4}$ with intersectionality positioned as a feminist attempt to "right the wrongs": "The term 'intersectionality' refers to both a normative theoretical argument and an approach to conducting empirical research that emphasizes the interaction of categories of difference" (Hancock, 2007: 63-64). Intersectional analysis endeavours to capture identity in its entirety rather than examining various components in isolation. Intersectionality, then, is ideally suited for contemporary feminist qualitative analysis and one that offers an appropriate theoretical framework for this project.

As others have pointed out, however, intersectionality has become a feminist cliché in both academic and activist circles (Davis, 2008; Hancock, 2007). Deemed necessary for legitimacy, it often focuses on the same few categories that ignore the importance of aging, for example. Some scholars have even gone so far as to label "race, class and gender" as a “"minimum standard' for intersectional analysis to which other categories can be added [...]" (Leiprecht and Lutz, 2006 quoted in Davis, 2008: 81). In turn, intersectionality is often used as shorthand for including race, gender or class into discussions, rather than as an analytical tool. For this reason, research like mine might not immediately register as necessitating an intersectional analysis. With such a narrowly focused category of white, elderly women who are poor, the multiple differences that comprise their identities may not be immediately apparent; however, there are invisible aspects that require an intersectional analysis. Questions that may be interrogated include: How do single women navigate poverty versus women with a living partner? How does

\footnotetext{
${ }^{4}$ The theory that there are cause and effect correlations.
} 
the experience of a lifetime of poverty impact one's perspective and practices versus someone who has only "fallen" into poverty in old age? Do formal education, geographic location and family size have an impact? What about experiences of paid versus unpaid work? There are many intersecting factors within these women's lives and to assume otherwise is to perpetuate the homogenization of elderly women. In this project, I do not undertake to answer all these questions; instead, I perform a critical intersectional analysis focusing on three sets of issues (transportation, care and food security) that recurred throughout the interviews. Although disentangling aspects of identity can be a useful exercise at times, analyzing identities in isolation limits the potential for understanding. In order to construct a more holistic picture of these women's lives, therefore, intersectionality is imperative and I organize my findings around three discrete issues to help support my argument about the need to think about how intersectionality can be employed to interrogate a range of identity markers beyond gender, race and class. As an activist and a researcher, I feel it is important to not only focus on the differences amongst these women but also their commonalities. Deconstruction is an important element of social science research but I feel it is equally as important to focus on the practical impacts of deconstruction. By focusing on the similarities between the 17 participants, my goal is to highlight ways in which we can move forward and keep the focus on the practical implications of being an economically disadvantaged elderly woman in rural and urban Ottawa.

Armed with my grandmother's story and a desire to put intersectionality to work, I was primed and ready to begin my qualitative research. Just when I thought I had figured it all out, I was struck by another unexpected turn of events. In late 2008 and 
early 2009, Ottawa experienced its longest (to date) transit strike mere days after I had received an approval from the Carleton University Research Ethics Board to begin my research. This meant that the vast majority of my interviews were conducted during the strike. For weeks on end, during the coldest weather of the year, commuters were stranded or scrambling for transportation. Many were completely isolated. This created a very frustrating and lengthy recruitment process as I struggled to access an already marginalized community. Although finding participants in this climate proved to be incredibly challenging, once the participants were found, it created an opportunity for the women to discuss their relationship to transportation, something many admitted they would not have thought of before the strike. The transit strike, therefore, became a major focus of the interviews and its impact on the participants became one of many examples of their resourceful and resilient spirit.

The transit strike, however, was not the only unanticipated element of my research. I began my thesis wanting to know about the daily experiences of economically disadvantaged elderly women. It was a large and seemingly depressing undertaking. With such staggering statistics as well as my own working-class family background, I anticipated long, arduous interviews. Although hardship and struggle were certainly important elements of these women's experiences, I was struck by their unlimited resilience and optimism. They were acutely aware of the difficulties in their lives but prioritized hopefulness over pessimism. As the researcher, I was constantly reminded that stories of "poor old women" were not their preference. Their resilience was a source of pride and it was my job to document these stories, while simultaneously giving voice to their struggles. I also want to complicate the concept of "resilience" by highlighting the 
ways in which it is tied to neoliberalism. By simply defining a marginalized population as "resilient", one can justify denying them further support services under the false belief that they are not necessary. It can also mean pitting marginalize groups against each other under the guise that since one group was "resilient", then the others must also govern themselves in the same manner (Joseph, 2013). I believe it is important to recognize the ways in which economically disadvantaged elderly women are resilient while also challenging the way in which that label can also be used to erase the barriers they face. Each of my 17 participants lived complex, intersectional lives and my work aims to highlight those nuances.

Although this is academic research aimed at generating qualitative scholarship on the lives of elderly women, this is also a project that relies on the life stories of my participants. Although I do not present a detailed account of each woman's life, I have the privilege in this thesis of assuming the dual role of researcher and storyteller. My project would not be possible without the willingness of these women to tell me their stories and I do not take that responsibility lightly. To allow a complete stranger into your home in order to discuss intimate details of your life requires a level of trust that I am proud to have earned. In retelling some of the stories shared with me by of some of Ottawa's elderly women, I am also retelling the story of 17 women's lives. As a feminist researcher, it is imperative that I recognize the women in my project as 17 distinct individuals with their own lives and experiences; to do otherwise would be to fall within the very same trap that I critique. To assume that women with similar identities inherently experience life in the same way ignores the nuances that intersectionality demands be recognized. However, my work also balances the need for an intersectional 
analysis with an examination of the commonalities amongst the women. To deconstruct indefinitely can be an interesting intellectual exercise, but it can be incredibly impractical as a means of creating social change. In balancing intersectionality with a focus on commonality, my work endeavours to have a practical focus that allows the conversation to move from theory to practice.

My thesis also afforded an opportunity for these women to document their own stories. The research provided a mutually beneficial relationship wherein I was able to learn from these experiences while, at the same time, contributing to a tangible archive of their life stories. Each participant was given a copy of their interview transcript, which was an obvious incentive for many. Few were keen about the process of being interviewed but were motivated by knowing that their stories would be documented and leave a legacy, not only in academia but in their own personal lives as well. The awareness that I was drawing on these women's life stories was never lost on me and the importance of doing it well weighed on me heavily. This project, therefore, serves two purposes. On the one hand, I contribute to feminist gerontology by shedding light on the daily reality of economically disadvantaged elderly women in Canada. Beyond that contribution, however, is the archiving of the shared stories from 17 women's lives whom I hope individually benefit from the fruits of this labour.

The thesis proceeds in the following manner. In chapter one, I scan the existing literature in the relative fields, such as gerontology, feminist studies and economics. I consider some contributions from these fields and identify the major scholarly gaps. I then present the theoretical framework supporting my work to properly situate my study within the literature. Following this, I introduce my participants, outline the methodology 
of my research and, in particular, explain why I chose to do qualitative, semi-structured interviews. I also document the unique circumstances surrounding the interview process and how the process of doing the interviews helped shape the project.

The next two chapters detail the central argument of my research. First, I present my major research finding that Canada's elderly women are resourceful and resilient. I define resilience as the ability to draw from personal strength to overcome hardship. Rather than existing passively, many elderly women actively create their own lives and contribute in ongoing, daily ways to the wellbeing of their communities. They navigate formal networks and create their own informal alternatives where gaps exist. They creatively overcome their lack of financial resources by drawing on their wealthy of social capital to triumph over adversity. Their resilience is truly remarkable. The second major finding of this research project, however, is that resilience is a complex term that cannot be viewed in isolation from the conditions that force people to be so tough. I critique how "resilience" has been employed by neoliberalism to promote an individualized approach to social welfare. It is imperative that we recognize the systems that force elderly women to work so hard to simply survive and resist the impulse to assume that their resilience means that policy changes to counter the economic disadvantage facing many elderly women is unnecessary.

Finally, I conclude by outlining specific recommendations that derive from the participants themselves. My narrators had very precise requests and recommendations for ways that communities, various levels of government and front-line workers could improve the lives of Canada's future elderly population. Their recommendations, in combination with my own observations, suggest spaces for future research in this field. 
The women whose stories I share in this thesis and I together hope that this project serves as a launching point for further inquiry and, ultimately, social change. 


\section{Chapter Two}

\section{Theoretical Framework}

An exploration into the daily lives of economically disadvantaged elderly women cannot be accomplished without examining previous work done in this area. The following literature review is organized to sift through existing literature on poverty, gerontology, place and space, intersectionality and social capital. It critically examines relevant research areas and emphasizes how available analyses remain insufficient for capturing the lives of economically disadvantaged elderly women in contemporary Canada. Finally, this review concludes by setting up the theoretical framework used for my own research and demonstrating how this project differs from the existing literature by emphasizing intersectionality, using qualitative methods and recognizing a lifetime of poverty.

\section{Literature on Poverty}

Literature on poverty is vast and crosses many disciplines, but the most important aspects for my research are the constructions and definitions of poverty and their impacts on the daily lives of marginalized populations. Although quantitative measurements are important, my work is situated primarily within the existing qualitative literature and analyses.

The first step in discussing poverty is to establish the parameters. Contrary to popular belief, Canada has no "poverty line"; multiple definitions of poverty exist. In fact, even the Government of Canada "has not officially adopted any specific measure of poverty" (Collin, 2007:1). The most commonly used definition of poverty in Canada is the "Low-Income-Cut-Off" (LICO) established by Statistics Canada. The method is best 
described as the "relative expenditure approach" in which Statistics Canada measures the average expenditures in the community (Canadian Council on Social Development, 1984. 13). Statistics Canada also uses the "Low Income Measure" (LIM) that defines "lowincome Canadians as those living in families that have an after-tax income lower than 50 per cent of the media income for all Canadian families in a given year" (Preville, 2003:1). In 2003, Human Resources Development Canada introduced the "Market Basket Measure" (MBM) which measures poverty by "estimate[ing] the cost of a specific basket of goods and services for a reference family consisting of two adults and two children living in a particular region for the year 2000, assuming that all items in the basket were entirely provided for out of the household income" (Ibid). These are a small selective sampling of poverty measurements used at the federal level and with so many measurements come variable results. For example, when using the LICO to measure poverty, Quebec ranks as one of Canada's poorest provinces. When the MBM is used, however, Quebec is one of the wealthiest provinces. Quantifying poverty in Canada is clearly difficult and doing so on a consistent level is almost impossible. However, it is easy to say that measurements of poverty are unreliable and therefore of little use, but a baseline of poverty is important for sustainable social security. With no consistent definition or measurement, it is incredibly difficult to allocate social services, prepare budgets or provide accurate projections. And therein rests the problem with simply employing a quantitative analysis. Doing so gives an inaccurate portrait of what poverty actually looks like in this country, particularly since there is no consistent baseline.

This phenomenon has been well documented by one of Canada's premier leaders in poverty research. The Canadian Council on Social Development (CCSD) has been at 
the forefront of research and policy development on poverty in Canada since 1920. One of its major findings was that Canada's measurements of poverty are inadequate and need to include factors such as the depth of poverty and the length of time spent in poverty (CCSD, 1984: 67). They also recommended that special attention be paid to the "feminization of poverty", which refers to the systemic ways in which women are susceptible to poverty. CCSD's critical examination of poverty definitions and measurements is crucial to understanding my own research. "Women Elders in Action" (WE*ACT), a grassroots group in British Columbia, has documented the double bind of inadequate and inappropriate measurements of poverty: "The lack of reliable numbers to support our arguments has been a challenge, which is partially why we've compiled research that describes women's earnings, time spent in the workforce, ability to save, and access to pensions" (Gerry Kilgannon, 2007: 2). The flawed nature of measurements has been well documented and since my project aims to uncover the lived realities of elderly women living in poverty, the use of strict measurements was not necessary. In fact, I specifically did not include a definition of "economically disadvantaged" in my research because I was more interested in the act of self-identification. By selfidentifying as economically disadvantaged, a participant would be naming their experience of exclusion, need and want, something that is not captured through a quantitative lens. Therefore, my own research uses a qualitative approach that employs self-identification as the measurement of poverty.

Another major flaw in poverty research in Canada is the way in which a gendered lens is applied. The "feminization of poverty" as a concept has been well researched and defined within feminist academic literature. The feminization of poverty refers to the 
disproportionate levels of poverty that women face due to systemic discrimination (Brady and Kall, 2008). The term has been used since the late 1970s, but typically focuses on the ways in which poverty is concentrated among younger women (Barusch, 1994: xxiii). And yet, we know that the gendered implications of poverty are felt throughout a women's lifetime and are, in fact, further impacted by age. A 2000 report on the feminization of poverty in Canada provided critical analysis of the "dynamics of women's poverty in Canada" but, as Lochead and Scott note, it was also guilty of narrowly defining the feminization of poverty as it looked at gendered poverty through the lens of young women and, in particular, single mothers (Lochhead and Scott, 2000). Although single mothers constitute an overwhelming number of women living in poverty in this country (and around the world), they are far from the only category of women who live this way. Elderly women live overwhelmingly in poverty and yet their experiences are completely invisible in both the discussion and the recommendations for change. For example, strategies proposed by feminist activists such as the creation of a national child care plan have the potential to alleviate poverty for young, single mothers and future elderly women, but they do very little for the elderly women currently living in poverty. They also do nothing for women who do not have any children. In fact, any anti-poverty measure that focuses on employment or child care fails to account for elderly women who do not view the market as an exit strategy. Access to the workplace might be a great anti-poverty strategy for many, but not for elderly women. We know that " $[\mathrm{g}] \mathrm{ender}$ inequality throughout the life cycle often results in women entering old age with far fewer resources than men" (Brown, 1998: 4). A gendered analysis of poverty, therefore, is absolutely essential for deconstructing the systemic ways in which women are 
oppressed and relegated to lives of poverty; yet, an age analysis is also imperative. This is where my work fits in. As I illustrate below, using a gendered and gerontology-informed lens, my research is able not only to highlight the lives of economically disadvantaged elderly women; it is also able to provide adequate and tailored responses to such poverty. Naming and shaming poverty is important. The process of identifying and, in turn, "shaming" the systems that create inequality is an important part of feminist research. However, being able to strategize around solutions is critical as well. Without using a gerontology lens to look at the specific realities of elderly women, the work is incomplete.

The last major element of poverty research that is important for my study is the literature around class as a social category and, more specifically, the stigma of poverty. In particular, I rely on two studies whose work predates my own. In the early 1990s, Amanda Barusch conducted research based on qualitative interviews 62 elderly American women from various backgrounds. The text closely resembles my own research in its methodology and tone. In conducting her interviews, one of the major difficulties she encountered was recruitment. This was not due to a scarcity of eligible participants but more that people resisted the label of "poor" and therefore did not come forward, even when they clearly fit the description. Barusch concluded: "People resist stigmatizing labels, so individuals advanced in years seldom consider themselves 'old', just as those with few economic resources seldom consider themselves 'poor"' (1994: 31). Her observations about the stigma of poverty and old age are important for understanding the context in which I conducted my own research. The women in my interviews had similar experiences as Barusch's and so her work speaks volumes about the universality of 
stigma, particularly around class. As important as it is to create categories of people in order to name and shame a problem, it is also important to recognize that there are people behind those labels, people who must live with the consequences of that categorization. This tension is important and something reflected in this thesis.

The importance of recognizing the stigma of labels is also apparent in the latest polling surrounding people's views of poverty in Canada. The Salvation Army of Canada recently polled Canadians about poverty in the hopes of debunking some popular myths. The results of this poll were published in a report that shows a stark representation of how Canadians view the poor and a life of poverty. What is particularly important for my work here is the ways in which the average Canadian firmly believes that the poor have it "pretty good" and could easily work their way out of poverty, should they choose to (2011). What the report shows is that people who reject the label of "poor" have a very good reason to do so. The stigma of living in poverty is real and has very dire consequences. Within my own research, this reinforces my use of self-identification because poverty is less about objective definitions and more about how you relate to others and/or are judged by others. Also, it speaks to the idea of the "deserving" versus the "undeserving" poor. By refusing to create a standard of what is and what is not "poverty", I am recognizing all those who identify as poor as "deserving". To further reduce the stigma of poverty, I changed my initial use of "poor" to "economically disadvantaged". It was important to use an accurate label while also balancing that need with the reality of how that label would impact the participants. Therefore, in speaking with a service provider about preferred labels, I decided upon "economically 
disadvantaged" as it demonstrates a lack of resources but emphasizes society's role in creating those conditions.

It is evident that literature on poverty in Canada is diverse and varies greatly from quantitative, statistical measurements to qualitative narratives of people's individual experiences. Quantitative research and analysis are helpful to the building of my own research but most of it fails to capture the qualitative realities of living in poverty and it certainly fails to address the lived experiences of elderly women. Quantitative research justified the need for my research but its general lack of an intersectional analysis leaves major gaps.

\section{$\underline{\text { Feminist Gerontology }}$}

The second major research area that is important for framing my own research is feminist gerontology. Mainstream gerontology, by definition, studies the social, psychological and cultural implications of aging (Levenson and Porter, 1984). Unlike geriatrics, which studies the physical aspects of aging from a medical perspective, gerontology is more concerned theoretically with the social realities of an aging or aged population. There is very little literature within the discipline, however, that concerns the social lives of the elderly. The absence of the social reality of the elderly in mainstream gerontology is directly addressed in Invisible Lives: Social Worlds of the Aged (Unruh, 1983). A short but comprehensive examination of the social lives of the elderly, it serves as a critique of mainstream gerontology and research on aging which has historically perpetuated the idea that as people age, they become less attached to their social lives and oftentimes are painted as outright anti-social: 
The notion of integration [to the social world] is carefully examined here, and prevailing conceptions based on it are cogently criticized for their overlooking of how older people may actually live satisfying and even exciting lives through various types of involvements that have either escaped the notice of gerontologists or not been properly assessed for their significance. (Ibid. 9)

Unruh concludes that understanding the lives of the elderly cannot be done without including their social lives. It is apparent, then, that my own work is better situated in the category of social gerontology: "Social gerontology deals with the nonphysical side of aging and includes the psychological, social psychological, and social aspects of aging" (Atchley, 1994: 18). Work such as mine, which deals with the social realities of a distinct group of elderly women, finds a home in social gerontology. Although physical health and mobility clearly impacts one's social life, my work aims to move away from simply viewing aging as a physical process and valuing "aging as a social process" (McPherson, 1983). We are not solely the makeup of our physical selves, but rather social creatures with families, friends, hobbies and interests. Nadasen's research on the social activities of elderly women in Cape Town, South Africa is a perfect example of this. Her project is a direct response to existing research on physical activity and the elderly (2008). Nadasen aimed to examine the nonphysical impacts and benefits of elderly women becoming involved in organized, community-based physical activities. This is a project that challenges the mainstream discipline of gerontology and fleshes out the full spectrum of benefits and challenges to aging on a physical level. Yes, as she ascertains, there are measurable benefits to an active lifestyle for the elderly; however, by using a social gerontology lens, she concluded:

[...] line dancing enabled these women to expand their repertoire of social activity, leading to positive reinforcements such as further community involvement, charitable work, inclusion in national sports events, self-expression, 
and personal development. The impact of line dancing plainly goes beyond the perceived physical benefits. (2008: 329)

Going beyond measuring the physical benefits of exercise, Nadasen is able to make a strong case for engaging the elderly in physical activity for reasons that extend past mere bodily health. Nadasen believes this makes for better policy, better research and an overall improved assessment of what it means to be elderly.

The major downfall of social gerontology, however, is that it often lacks a gendered analysis. Feminist gerontologists have argued that gerontology fails to include a gendered lens whereas feminist literature frequently fails to examine aging. Clary Kerkula challenges gender theorists and social gerontologists to question a variety of assumptions that permeate the disciplines (2007). In particular, she challenges "double jeopardy theory," which is the "assumption that prejudices and discriminations against a minority group are worse when combined with prejudices against another disadvantaged group" (161). For example, by assuming that elderly women are inherently more disadvantaged than elderly men because of sexism and ageism, we fail to consider the ways in which elderly women are often cushioned from the effects of old age by having strong social networks, something many elderly men lack. Although she recognizes that elderly women experience oppression based on the combination of their gender and age, she challenges the way in which social gerontology has framed the lives of elderly women as inherently pessimistic and miserable: “[...] in social gerontology, the double jeopardy perspective has been a dominant way of problematizing the interaction of age and gender. Thus, the focus on the interaction of age and gender has primarily resulted in 
a simplistic misery perspective" (163). This particular element is important to my own research.

Although my project includes an intersectional approach that often includes the "double jeopardy theory," my research actively resists the idea of the elderly woman as victim. This is where I would argue that Kerukla is guilty of simplifying the reality of elderly women's lives. It is not inherently disempowering to frame elderly women's lives within a "double jeopardy." To recognize the layers of oppression that they face based on their gender and age is not to silence them. The silencing occurs when elderly women are researched as simply passive victims of oppression. Instead, what is needed is an understanding of the struggles that elderly women face within our sexist and ageist society and recognition of the ways in which they actively resist this oppression. It is within the analysis of their methods of resistance that we can disentangle the ways in which elderly women are often equipped to defy the barriers placed before them. Nonetheless, Kerkula's work is important for my own as it challenges the lack of a gendered analysis within mainstream and social gerontology while also questioning general assumptions within the field. She speaks to the need for a comprehensive gendered analysis within social gerontology and makes the case for feminist gerontology.

Not surprisingly, the area of research within gerontology that is most reflective of my own work is feminist gerontology. Feminist gerontology constitutes a relatively new branch of gerontology and actively challenges the lack of a gendered lens in gerontology while critiquing the lack of gerontology in feminist studies. Fundamentals of Feminist Gerontology is one of the primary texts in the discipline (Garner, 1999). From the outset, the author establishes both herself and her writing as feminist. Garner's work is important 
if for no other reason than its analysis of the relationship between feminism and gerontology. According to Garner: "Feminism recognizes the intrinsic value of women, their right to equal treatment, and their right to be viewed as individuals. Gerontology recognizes the intrinsic value of older people, their right to equal treatment, and their right to be viewed as individuals" (1999: 6). She is quick to point out, however, how both feminism and gerontology have failed elderly women by either focusing too much on younger women, in the case of feminism, or completely neglecting a gendered perspective, in the case of gerontology. The marriage of the two is what interests Garner and other feminist gerontologists. A chapter of particular importance to my work is that written by Ruth E. Ray, a prominent feminist gerontologist (Ray in Garner, 1999: 171184).

Ray calls for feminist gerontologists not only to fight to include women's voices in gerontology and vice versa, but to question the epistemology of the discipline with the result being what she calls "critical gerontology." She argues that gerontology is currently multidisciplinary but that it should take perspective from feminism and become interdisciplinary; a "mutual interaction" (Ibid.: 173). This would involve combining qualitative with quantitative research, for example, and questioning academia's fixation on objectivity. This is where Ray's work becomes crucial to my own. She makes a case for the importance of qualitative research in gerontology and, more specifically, the voices of elderly women themselves. Feminism and gerontology have been guilty of silencing elderly women. In both cases, the voices of elderly women are missing, something that my research aims to address. 
Calasanti and Slevin recently edited an anthology that is crucial to the expansion of feminist gerontology. Age Matters "urges a shift in how feminist scholars approach the study of inequalities by demonstrating how and why age matters" (2006). Calasanti and Slevin explicitly call on feminist scholars and mainstream gerontologists to recognize the gendered nature of age relations. This particular text is also noteworthy because it includes Canadian content. Julie Ann McMullin and Ellie D. Berger examined the lives of unemployed older workers in the Greater Toronto Area. Using qualitative, semistructured interviews, McMullin and Berger discover that it is almost impossible to tell whether the workers were discriminated against based on age or gender. Ageism and sexism are so intrinsically linked that in order to improve the likelihood that older women will get hired one must address systemic inequalities on multiple fronts. The researchers point out: "if the subject of analysis involves the intersection of gender and other bases of inequality such as age, the gender concept must not take an a priori emphasis over other dimensions of inequality" (McMullin and Berger, 2006: 203). McMullin and Berger's work is important to my own research because it speaks to the importance of intersectional analysis that moves beyond simply race and class. By recognizing the inseparability of ageism from sexism, the researchers demonstrate that intersectionality has an important practical purpose; in this case, improving the working conditions of older women seeking employment in Canada. Their work is also important for this thesis because of its methodology. Using qualitative interviews, the researchers centre their analysis on the voices of the women affected, rather than simply sifting through statistical data on, for example, unemployment rates. 
Feminist gerontology is a relatively new and developing field and, unfortunately, it "continues to be seen as a specialized approach within gerontology overall, unable to contribute to knowledge about aging in general" (Calasanti, 2009: 471). With academic heavyweights like Toni M. Calasanti, Kathleen F. Slevin, and Ruth R. Ray publishing extensively on the issue, it is clear that the field has much potential for growth and development. Still in its infancy, however, the field is likely to continue challenging gerontology and gender studies, particularly if it involves further Canadian content.

The discipline remains relatively marginalized overall, but there is a particular dearth of Canadian research. With an increasingly aging population, I am hopeful that research in this area will increase in popularity. Evidently, as a Canadian feminist researcher examining the lives of elderly women in Canada's capital, my work provides a much-needed dose of Canadian content. Furthermore, as a young scholar, I look forward to the development of the field in the years to come.

\section{$\underline{\text { Place and Space }}$}

The relationship between gender, age and class is a major element of my research project. Another important element is the way these relationships are impacted by one's geographic spaces and the places inhabited. Does an elderly woman's life of poverty differ if she lives in an urban or rural setting? How does where aging occurs, both in terms of location and housing type, matter? The research in this area is diverse and crosses many disciplines including sociology, anthropology, geography, gerontology, etc. It also has theoretical and practical applications. For the purposes of my own research, the most important aspects are community settings, housing structures, and mobility. 
When I initiated this project, I wanted to compare the reality of rural women versus urban women. Looking at the issue from a strictly quantitative lens, there are clear differences in the quality of life for both groups of women (Wanless, Mitchell and Wister, 2010: 235). In Jean Pearson Scott's analysis of the stability and change in family interaction patterns of rural women, she discovered: "[I]n rural areas, women have poorer housing, limited access to medical and social services, and higher rates of poverty in comparison to older, urban women" (1998: 68). Furthermore, their attachment to the land created an element of anxiety for them, because if their health and economic situations became too dire, they would not only lose their independence by requiring assistance but may also have to move to an urban, populated area where social services are more readily available. The valuing of independence for elderly people is commonly understood, but the added element of being removed from one's land is a fairly unique experience that is not seen as often with urban women. Scott's research project is therefore important for two reasons. First, it highlights the quantitative reality of rural women and exposes the very tangible ways in which rural women are disadvantaged but, secondly, it demonstrates the importance of a qualitative lens. In using qualitative methods, Scott is able to move beyond simply comparing the bank accounts of rural women with that of urban women. Instead, she is able to demonstrate how rural women fear dire poverty and lack of independence because it means leaving not only their home but their hometown. Her combination of quantitative and qualitative research methods creates a more nuanced portrait of what life is like for women in rural areas. Although her work has a much narrower focus than my own, her use of qualitative methods as a means of understanding the relationship to location and the importance of community is mirrored in my own. 
Similarly, Dena Shenk's analysis of “The Subjective Realities of Rural Older Women's Lives" actively critiques the ways in which the lives of rural women are rarely treated to a qualitative analysis (1998). She notes similar statistics to Scott's in relation to objective poverty for rural elderly women, however "other accounts characterize rural women as advantaged, noting their supportive networks and strong ties to the community" (Ibid.: 8). She goes on to speak of one rural elderly woman as a case study for how quantitative measurements of poverty might paint rural women as inherently disadvantaged and, yet, the rural community setting creates a more supportive environment that allows people to not only survive, but flourish. Comparatively, Craft, Johnson and Ortega's 1998 research in this area found "that the urban elderly expect and receive less assistance from others" as opposed to rural elders (6). One cannot make any conclusions about the quality of life of elderly people in rural or urban areas without including qualitative methods. The rural ties to land and a strong sense of community help cushion these women from the perils of poverty. This is something that would not necessarily be acknowledged in a quantitative study. More than just offering a comparative methodology, however, these works speak to the importance of geographical location to the lives of economically disadvantaged elderly people. Their work highlights how there are tangible differences in the lives of rural versus urban women but that the very place that creates this objective poverty can also be used to cushion oneself from the effects of it. Even though it makes economic sense for rural women to leave for urban areas, the loss of independence combined with the detachment from the land means a diminishment in the quality of life for these women. This relationship between women and the space they occupy is a major element of my research and is helpful for 
understanding the ways in which my research participants cope and strive in such arduous conditions.

A second important aspect of research in this area involves the actual dwellings in which elderly women live. The issue of housing is familiar to many who are dealing with an aging parent or relative. In Canada, discussions around housing for the elderly typically fall into camps: living independently or living in a retirement facility. An elder's decision on their housing situation, assuming it is their decision to make, involves much consideration. The research demonstrates that elderly women overwhelmingly prefer to “"age in place', remaining in houses that may fall apart around them to enjoy the benefits of a home"" (Barusch, 1994: 124). This was my experience when conducting my research. Due to the inherent and deliberate "community environment" of retirement homes and assisted living facilities, I deliberately excluded participants who lived in these settings. Instead, I wanted to focus on those who live at home, with a partner or with family and whose sense of community (or lack thereof) was organic. One of the best scholarly starting points in this area is Smith and Sylvestre's "The Effects of Neighborhood and Individual Change on the Personal Outcomes of Recent Movers to Low-Income Senior Housing” (2008). This Canadian study set out to understand how elders felt about their recent relocation to a "government-subsidized senior citizen apartment building (SCAs)" (592). Many of the participants in my research live in a variation of a SCA and so this quantitative study provides a good background for understanding my own qualitative data. The researchers surveyed Winnipeg residents over 55 who were fully retired and lived in a SCA for at least a month but less than a year. They re-submitted a different survey one year later. The questionnaires were 
structured and therefore allowed Smith and Sylvestre to measure quantitatively satisfaction levels on issues ranging from self-rated health, morale, levels of depression and self-esteem. The research results are complex and include a variety of factors not important for my research here, but one important finding is that respondents reported better satisfaction when the move meant closer proximity to essential services, such as food and health services. Many respondents reported that living in a SCA meant connecting to a new network of support. What this means for my research is that the description of one's dwelling is less about the physical structure but what that structure gives one access to. In this case, SCAs often mean a network of people in similar situations who can provide formal and informal support, should it be needed. Their work highlights elder attachment to living space and how moving from one location to another creates its own unique problems for people in their later life. This study and my own research together explore how quality of life is impacted by place and space.

The last important element of this research is the examinations of mobility and in particular, transit. A text of major significance for understanding the importance of mobility is the World Health Organization's guide to Age Friendly Cities (2007). The guide focuses on the intersections of two major global trends: aging populations and rapid urbanization. It is based on research conducted in 35 cities from every continent with the goal of developing strategies for the inclusion of the elderly in modern cities. The guide is focused almost entirely on practical concerns, ranging from the best outdoor seating to the best ways to engage elderly entrepreneurs. Of particular relevance here is Section 6: Transportation. The research on transportation concluded: "Being able to move about the city determines social and civic participation and access to community and 
health services" (2007: 20). Although public transportation or housing structures appear to be practical, tangible things, they clearly have a substantial impact on the quality of life for elderly people. The Guide is incredibly relevant to my own research for it very clearly makes the case for the inclusion of elderly people in city planning. By combining data from around the world, the guide speaks to the universality of the elderly experience in urban spaces and reinforces the importance of one's place of residence and mobility. As an activist researcher interested in practical solutions, my research meshes well with the messages in this important guide.

With a similarly applied focus, Engels and Liu's research on the social exclusion of elders without vehicles in Melbourne lays the groundwork for a broader understanding of the importance of public transit for the elderly (2011). Their research combines city planning with sociological understandings of exclusion to examine elders in Melbourne who do not drive but live outside the radius of public transit. As the population ages and the Melbourne city limits expand, there are more and more elders in need of reliable transportation and yet many are physically or financial unable to drive. Using strictly quantitative methods, Engels and Liu measure the accessibility of the city for elders within the municipality of Melbourne. Their research concludes that "transport engendered social exclusion" is a reality that is bound to worsen as the population ages (984). This study has important implications; however, it is too specific to the city of Melbourne to be taken as universal. Additionally, their reliance on exclusively quantitative methods means that other relevant elements are missing. Although my own research supports their conclusion, which is the need for elder-friendly transportation, their lack of qualitative data translates into a lack of concrete solutions. Without the 
voices of the elderly or even elderly-sensitive city planners, the conclusions are weak. In fact, their main conclusion is that further research is needed in this area in order to brainstorm solutions on how to redress the current exclusion of non-driving elders. With that said, overall the study is an excellent example of the importance of understanding mobility as far more than a system of public transit but rather as an integral element of an inclusive society.

\section{$\underline{\text { Intersectionality }}$}

The core of intersectional analysis is recognizing the "mutually constitutive relations among social identities" (Shields, 2008: 301). Intersectionality is a central tenet of feminist theory that occupies the space "between reductionist research that blindly seeks only the generalizable and particularized research so specialized that it cannot contribute to theory" (Hancock, 2007: 74). My major criticism of intersectionality, however, is the way in which it has become a "buzzword", something that Kathy Davis explores in her research (2008). In her article, Davis excellently captures the essence of intersectional theory's major flaw: it has become popularized to the point that it is often misapplied and rarely deconstructed. Her work questions, "[...] how a theory which is so vague could come to be regarded by so many as the cutting edge of contemporary feminist theory" (69). Davis discusses how an intersectional approach became the de facto feminist theoretical model yet is so rarely questioned. Davis unpacks intersectional theory from its initial use by Kimberlé Crenshaw in the late 1980s to its present day usage. She discusses my major concern with intersectional theory, which is that it is actually a euphemism for adding race, sexuality and class to a gender analysis. As 
someone who interviewed 17 white women from similar class backgrounds and social locations, my use of an intersectional analysis is not obvious. What differences could these women possibly have that would require an intersectional approach? The answer, according to Davis, is plenty. Gender, class, age, geographic location and social status are all intersecting identities that cannot be viewed in isolation but rather understood as inseparable. My participants live complex lives with intersecting oppressions that are often rendered invisible by a narrow definition of intersectionality. Davis' work concludes by stating that intersectionality, or rather a nuanced intersectional analysis, is the ideal feminist theory that should be improved upon rather than scraped. She argues that intersectionality "encourages complexity, stimulates creativity, and avoids premature closure, tantalizing feminist scholars to raise new questions and explore uncharted territory" (79). For my own research project, Davis' article informs my theoretical and methodological approach.

Working at the crossroads of gerontology and women's studies is Toni Calasanti. One of the most prolific feminist gerontologists, Calasanti's work examines the lived realities of elderly women while also offering an impressive analysis of the discipline itself and highlighting the notable absence of elderly women's lives within gerontology. For example, Calasanti observes that in a series of journals on gerontology between 1998 to mid 2003, not a single article included the terms "feminist" or "feminism" (2004: 2). I have already discussed at length the importance of feminism's inclusion into gerontology but I include Calasanti's text here because she speaks of the importance of an intersectional analysis that is fairly unique. First, the call for more research in feminist gerontology is an inherent endorsement of intersectional analysis. When women age, they 
are both women and old at all times; they cannot simply pick and choose which identity represents them. We know that women's experiences of aging are unique and their oppression is as much about sexism as it is ageism. Secondly, and most importantly, however, Calasanti's work addresses the ways in which an intersectional analysis is beneficial to all genders. In this sense, her work mimics that of Davis in advocating for a nuanced intersectional approach. Calasanti believes that by applying an intersectional analysis to all areas of aging studies, we can move the theory from the margins to the mainstream. As an example, Calasanti discusses how feminist gerontologists vocally advocate for an intersectional approach "but then begin to talk about poverty in old age only in terms of women - without subsequently contextualizing or acknowledging that White women are less likely to be poor than are Black or Hispanic men" (4). This example speaks to my own work. On the surface, my participants appear to be incredibly homogenized and yet, once an intersectional approach is applied, the complexities of their lived realities begin to emerge.

Calasanti's work also briefly discusses another important element of intersectionality that I have yet to see articulated elsewhere. She advocates for an intersectional approach to be used not only on research subjects but on researchers themselves. More specifically, she calls for further discussion and research on the power dynamics between researcher and participant when the participant is old and the researcher is not. Intersectionality needs to move beyond the three main tenets (gender, race, and class) and include age in a way that recognizes age relations. What do the interactions between researcher and subject tell us about age relations? How do the two interact when there are clear generational differences? As a researcher who began this 
work in my early 20s, I was acutely aware of the ways in which our youth-obsessed culture awarded me power over my participants in a way that went simply beyond the researcher-subject relationship. Calasanti's work is a significant contribution to the understanding of intersectional analysis and the importance of constantly reevaluating its uses.

\section{$\underline{\text { Social Capital }}$}

The last important research area crucial for understanding where my own research is situated is social capital. A term popularized by Robert D. Putnam, social capital refers to the currency and benefits associated with social networks. Putnam's Bowling Alone was a pivotal text that popularized discussion of the ways in which North America was shifting away from interdependent communities to households living in isolation. Putnam's framing of social capital as a measurement of quality of life is seen in my own research as the role that social capital plays in the lives of my research participants cannot be underestimated.

Aurélie Brunie examines social capital from a theoretical perspective (2009). Brunie argues that much like intersectional theory, social capital is a term that has become so ubiquitous that it is rarely deconstructed. In her view, both the defining and use of social capital has been overused and has therefore lost its strength. Although its proliferation has meant the advancement of our understanding of the concept, it has also meant the stretching of the concept to the point where it is often so broad as to become useless (252). Brunie categories social capital into three unique approaches: relational, collective and generalized. In the relational approach, social capital is tied to individual actors in a network and examines a network from the perspective of the individuals 
within it and their access to resources. The collective approach examines social capital from the perspective of a small, tight-knit group. Here the focus is less on the "instrumental utility of a specific actor's relations [than] the quality of the relationships among actors within a collectivity" (255). Finally, in her view, the generalized approach to social capital conceives of it as subjective and as an individual attribute: "It is not a group that builds trust, but rather its members who acquire particular values and attitudes" (257). Her breakdown of social capital is incredibly important for understanding my own research. Although my work blurs several of the categories, the approach that most defines it is the collective approach. The participants in my research who were able to persevere through difficult times were able to rely on the help of those in their familial networks. Although all of the women had access to some sort of formal network, they were drawn to those they knew personally. Trust and feelings of history and familiarity defined their primary networks. As Brunie outlines, "[m]utual trust is the central factor in facilitating voluntary cooperation and it arises from norms of reciprocity and networks"; the women are able to rely on these networks because they are also relied upon by those very same networks (255). Brunie's work contributes significantly to research on social capital for she helps to deconstruct its various applications in an effort to strengthen its overall usefulness as an analytic category. Her work also highlights the links between social capital and resilience, as she demonstrates how resilience is born from being rich in social capital. In my own research, strong social networks are a source of strength for the women; they contribute to their capacity for resilience in the face of hardship. In this sense, Brunie's work is a crucial text for understanding the lives of my 17 participants. 
James S. Coleman's examination of social capital is one of the earlier texts on the subject. It begins with a theoretical analysis of social capital and the history of its uses, and ends with analysing its practical application through a case study of high school dropouts. Much like Brunie's work, Coleman critiques the use of social capital analysis, claiming two major common mistakes. When using it in a sociological context, actors within social networks are victims of the environment they are in and have no "internal springs of action that give the actor a purpose or direction" (1998: 96). Equally as inaccurate are those who believe that actors within social networks are strictly motivated by selfishness and personal objectives. In this second category, there is no real understanding of collectivity or "greater good". I agree with Coleman's suggestion that the reality lies somewhere in between. Building social capital has benefits for the actor in question and the other actors in the networks; it is a mutually beneficial relationship that relies on each individual member to make the network successful:

If physical capital is wholly tangible, being embodied in observable material form, and human capital is less tangible, being embodied in the skills and knowledge acquired by an individual, social capital is less tangible, for it exists in relations among persons. (100-101)

Using this definition, Coleman looks at high school students and their likelihood of becoming dropouts, depending on their social capital. What he uncovers is that students with strong familial social capital had higher rates of success. More than any other factor, the relationship between parent/guardian and child decided the student's academic success. Social capital, as others have pointed out, relies on trust, reciprocity and "information-flow capability" (119). The reciprocal nature of social capital is particularly important for my work. My participants were quite cognizant that their informal networks required nurturing and that you only relied on others because you make yourself available 
to help in return. Although Coleman's research is now dated, it is still important for its deconstruction of social capital and for its emphasis on the mutually beneficial nature of human networks. It has clear links to my own research, where my participants' relationships with friends and family relied on reciprocity. The women could rely on their informal networks because they felt that it was a push and pull relationship.

An excellent starting point for the practical applications of social capital is a 2010 survey on social determinants of health by Wanless, Mitchell and Wister. Their goal in undertaking the research was to examine the impact of rural or urban location on the health status of elderly women. Using social determinants of health such as education level, economic status, employment history, etc., the researchers confronted a major contradiction:

On the one hand, lower individual and household income and lower education status are more prevalent in rural areas, and both are associated with poorer health status. On the other hand, research suggests that rural residents receive more social and community support (indicating a higher level of social capital), which are associated with better health status. (2010: 233-234)

This contradiction challenged their understanding of social determinants of health. If economic wealth is considered as important an indicator as social capital, then how do you measure the health of rural elderly women? Their extensive research study is actually unable to answer that question. In fact, their major conclusion is that the social determinants of health model is flawed and cannot be understood as universal. With so many factors intersecting and, in cases like this, contradicting each other, it is impossible to accurately determine the social determinants of health. But what is most important about this research for my own purpose is the quantitative evidence that social capital has a positive effect on the physical elements of aging. Although exact measurements of the 
hierarchy of social determinants of health are obviously subject to challenge, the researchers are able to prove that a strong social network and a higher stock of social capital helps cushion elderly women from the perils of poverty and aging. Social capital as a buffer against the ill effects of poverty is a consistent element of my interviews; in fact, this theme quickly appeared and inevitably drove the research conclusions. For the women in my research project, resilience was born directly from the wealth of their social networks. In times of need, the women could draw on their social networks to help them overcome adversity. The link between resilience and social networks is made clear in Wanless, Mitchell and Wister's text.

Another practical example of social capital's importance in the lives of elderly women is a study undertaken by Japanese researchers who followed a group of elders for five years in order to examine how interaction with their family and friends impacted their survival (Morita, Takano, Nakamura, Kizuki and Seino, 2009). Surveying over 5000 local elders, the researchers measured place of living, walk-related motor functional independence, social engagement, marital status, lifestyle and health status over the course of five years. Their results determined that social capital does impact one's mortality. Higher rates of social engagement and strong familial ties were "significant predictors of 5-year survival among" the elderly (546). What is most interesting for my research is that social capital and community engagement were particularly strong predicators of survival for elderly women. In fact, 82 per cent of women with a "strong sense of neighbourhood attachment" and interaction with family and friends survived at least five years, as compared to 70 per cent of men. This research, like Wanless et al.'s, uses quantitative research methods to prove the importance of social capital to the 
livelihood of elderly women. Its observations are useful and relevant to my project, but their conclusion needs to be put in context. The researchers based their study on Japanese elders and "Japan is considered to be one of the healthiest countries in the world, having been shown to have the longest life expectancy and longest healthy life expectancy, in particular among women" (543). Although the link between social capital and health can be universalized, in this case it must be situated within a very specific context where the environment is already conducive to a long, healthy life. This is certainly not the case in Canada. Although the life expectancy for Canadian women is 83 years old, social isolation and chronic health problems play a major role in reducing quality of life, as compared to countries like Japan (Milan and Vézina, 2012). Nonetheless, their research offers an invaluable quantitative analysis of the role of social capital and provides an excellent baseline from which my work builds.

It is now evident that my research situates itself within the existing literature on poverty, feminist gerontology, place and space, intersectionality and social capital. My work uses these works as my foundation and provides a much-needed contemporary, qualitative, Canadian analysis that represents the voices of economically disadvantaged elderly women. The following chapter outlines the methods and methodology used to achieve this goal. 


\section{Chapter Three}

\section{Methodology and Methods}

Qualitative interviews form the core method of the thesis. I followed feminist research principles by critiquing objectivity, recognizing marginalized voices and constantly engaging in self-reflection. As mentioned in my introduction, standpoint theory was critical to the planning and eventual success of this project. My work was informed by the basic tenet of standpoint theory: acknowledgment of one's perception and the privileging of certain perspectives (Tanesini, 1999: 138-139). Standpoint theory critiques objectivity and challenges the notion of a neutral perspective void of influence or opinion. Scientific research typically privileges the knowledge and information of "objective sources" as defined by the so-called absence of viewpoint. In this model, objectivity is the ideal and seen as truth, whereas those who do not fit the definition of "objective source" are seen as biased, one-sided and untrustworthy: "Hegemonic 'universal' knowledge has tended to ignore and render invisible marginalized experience, imagination and knowledge" (Stoetzler and Yuval-Davis, 2002: 327).

Standpoint theory not only challenges the existence of objective truth but also makes a claim for the importance of subjectivity. Epistemologically speaking, this means making space for the perspectives of those who are outside the margins of so-called objectivity because they offer an outsider perspective removed from the benefits of the system. Marginalized people do not benefit from the status quo and are therefore better equipped to judge or comment as they are less likely to be blinded by the positive aspects of the system in question (McClish and Bacon, 2002: 28). 
Although I subscribe to the second-wave feminist perspective that women constitute a marginalized category in societies across the world and, in this case, Canada, I do not believe in "women" as an essentialist category (Bryson, 2000: 199). I do believe that bodies read as female share commonalities in this country, but I am not solely privileging the category of women. In my research, I dealt with a category of people who were labeled as women, elderly and economically disadvantaged, none of which are traditionally understood as privileged positions to occupy. Due to their existence on the social, economic and political margins, I believe these women are well equipped to analyze the current economic and societal systems in Canada.

The decision to rely on qualitative research was clearly in line with feminist theory and methodology but my employment of qualitative research also responded to the reality of poverty discourse in Canada. Perhaps the most problematic aspect of the literature surveyed in chapter two is how poverty is defined. As mentioned, Canada does not have an established, universal measurement of poverty. The Canadian Council on Social Development, however, argues that there are many different purposes for the measurement of poverty, including the need to budget for programs accordingly, the need to plan long-term anti-poverty objectives, the planning of individual budgets for those who rely on social assistance and the reality that how poverty is defined greatly affects how it is publically perceived (1984: 7-8). Clearly, different measurements serve different purposes but most measurements fall within one of two camps: objective or relative poverty. The use of an objective measurement is "based on the belief that one can determine the absolute measure of poverty by examining the essentials necessary for physical survival" (David Ross and Richard Shillington quoted in deGroot-Maggetti, 
2002: 4). Relative poverty is based on the belief that one's scarcity of resources and quality of life is relative to others and is largely comparative.

Although an absolute measurement is important, as the Canadian Council on Social Development has pointed out, it fails to capture the whole picture. What about those who are living just above a so-called "poverty line"? What about those who have just recently fallen into poverty versus those who have experienced a lifetime of it? When looking at the elderly, it is important to recognize that those who experience poverty in their $60 \mathrm{~s}$, $70 \mathrm{~s}$ and 80 s have quite a different experience than those who are still considered part of the workforce, for example. All of these factors affect how one lives and experiences poverty and it is for this reason that I abandoned the notion of "measurements" in my research. For my purposes, I was more concerned with one's sense of belonging and ability to "make due" more than anything else, hence why all the participants were asked to self-define only.

Feminist epistemology also informed my understanding of my own positioning within the research. Throughout each step of the research process, I was aware of my privilege and actively challenged the notion that I was the expert. I did this by consistently prioritizing the voices of the women I interviewed and ensuring that their perspective led the direction of this project. It was my goal to constantly reflect on my location within the project and be aware of and try to minimize the power dynamics at play between researcher and participant. Certainly, the impact of the age differential was evident even at the beginning of the research. At the time of the interviews, I was in my early twenties and interviewing women over 65 . This meant that I was the age of most participants' children or even grandchildren which created an interesting dynamic. The age differential 
between the participants and myself meant, perhaps, that I was perceived as less intimidating upon my arrival. Although I was a stranger entering their home, I was perceived as less of a threat because, as many of the participants noted, I reminded them of their grandchildren. It is possible, however, that this association meant an aversion to presenting things in a negative light. It is possible that participants 'sugarcoated' facts in an attempt to soften their experiences for me. Existing research on the experiences of interviewing elderly women indicates that while "older people are more likely to admit women than men into their homes, [they] may also be suspicious of very young women" (Wenger, 2001: 264). Previous studies have found that elderly research participants saw extroverted, middle-aged women as the ideal researcher (Ibid; Kestin van den Hoonaard, 2005.). There was no way to investigate whether my age factored into how participants responded to my interview, nor did I attempt to, but it is worthy of note.

From the outset, power dynamics between the participants and myself were inevitable. I was entering a woman's personal space as an educated researcher with a certain set of knowledge that I was bringing to the table. I came to each interview in my own car with paperwork and an audio recorder and was therefore perceived to be the "one in charge". In order to create a shared power relationship, I attempted to humanize the process as much as possible. I arrived for each interview with flowers for the participant as a thank you. I began each interview with background information on my motivations for doing the research, which included disclosure of my being the first person in my family to attend university and the fact that I grew up living with my grandmother and great-grandfather. I also spoke about being new to the Ottawa area and, whenever possible, spoke of my relationship with the person who had put me in contact with them. 
In keeping with feminist methodology, and standpoint theory in particular, self-disclosure was important for establishing my perspective and for demonstrating that my position was not necessarily epistemologically privileged; I did not have the answers nor did I claim to (Tanesini, 1999: 138). I would follow up my background introduction by explaining that the interviews were semi-structured and therefore would follow an order and flow most comfortable for them. This emphasized that they were the experts and that my role was simply to listen and make note of their experiences. I also explained that each participant was free to refuse any question with which they were not comfortable and that they could refuse participation at any time during the process, including after their interview had been conducted. ${ }^{5}$ I accentuated that there were no right or wrong answers and that my goal was to understand their experiences and not to analyze or diagnose them. The use of semi-structured interviews rather than structured interviews or a survey was one more way in which I tried to create a mutually respectful relationship with the participants.

Since none of the participants had taken part in a project like mine, they relied on me to explain the process and structure the actual interviews. However, I was equally as dependent on them since they were the gatekeepers of information. Therefore, by explaining my background, explaining the interview process and then giving them the floor, I hoped to shift the power back to them as much as possible given the circumstances.

\footnotetext{
${ }^{5}$ See Appendix A for interview questionnaire.
} 


\section{$\underline{\text { Recruitment }}$}

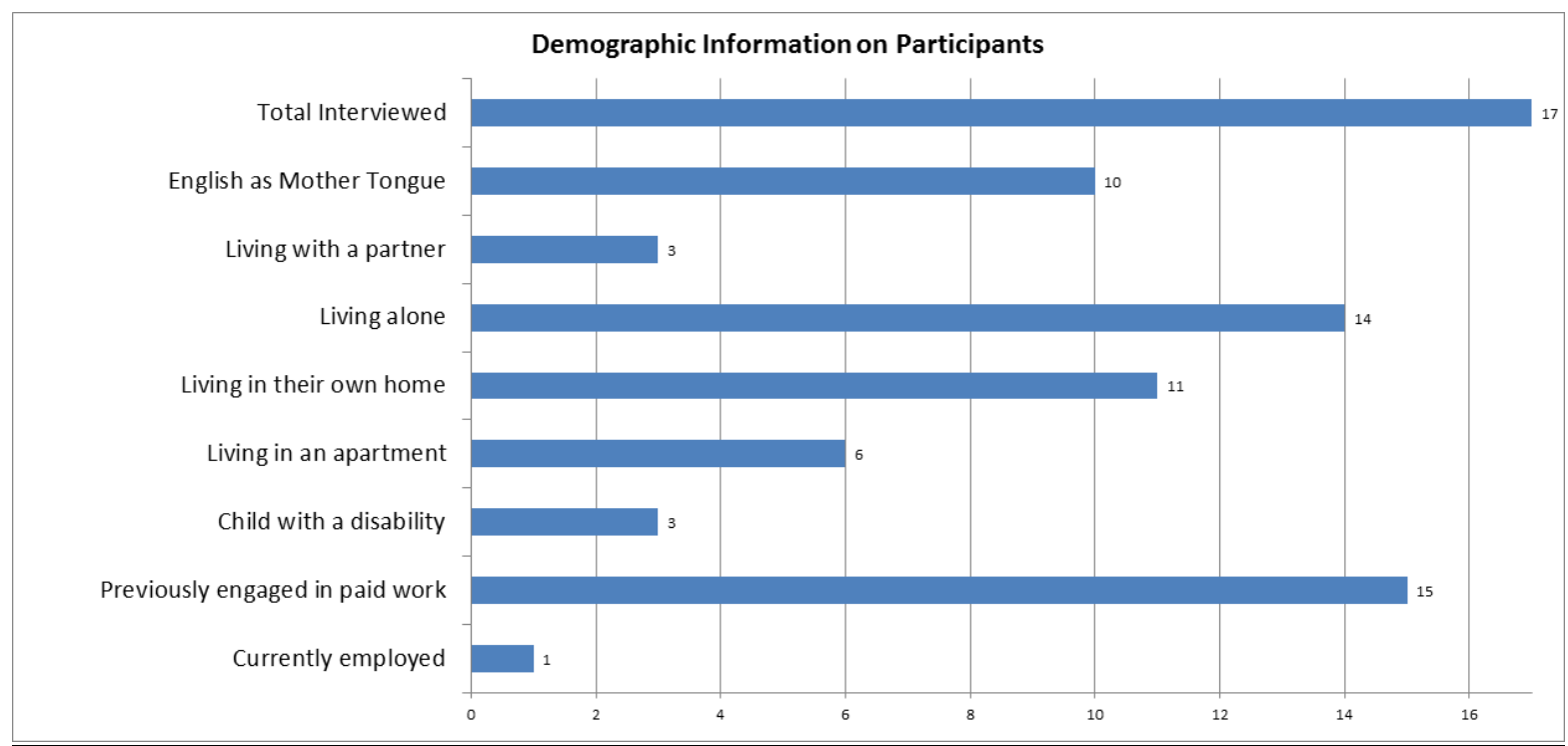

My research sought 18-20 elderly women living in urban and rural Ottawa who were over 65, Canadian, did not live in a retirement facility or formalized senior residence and who self-identified as economically disadvantaged. I used the term "elderly" in my recruitment and in my discussions because it is an honorary term for the wise and knowledgeable members of a community in many Indigenous cultures. Although the term "senior" is the term used by the state and was used by many of the women themselves, I maintained my use of "elderly" as it is less attached to age as it is to wisdom and insight. For this project, rural is defined as the upper Ottawa Valley; my rural participants derived mainly from Eganville. I also limited my interviewees to women who live alone or with family members because it was beyond the scope of my project to address the unique situations of women living in residential retirement and nursing homes. Those women live in environments that present unique situations regarding community and isolation that fall outside the scope of this investigation. 
The means of recruitment initially proposed for urban participants were posters distributed to various community resource centres in urban Ottawa, such as community health centres and senior drop-in centres. This proved ineffective for a few reasons. Considering the reality of living in a major urban setting, it is understandable that a poster asking for participants to meet with a researcher to discuss their experiences of being economically disadvantaged would be somewhat suspect. Secondly, my recruitment poster included the descriptor "elderly women living in poverty," a phrase that proved to be off-putting. As Barusch explains: "People resist stigmatizing labels, so individuals advanced in years seldom consider themselves 'old', just as those with few economic resources seldom consider themselves 'poor"' (1994: 31). It is clear that when dealing with a population that is both "old" and "poor", one must consider their language and terminology carefully. After speaking with service providers in various community centres, they recommended that I use the term "economically disadvantaged" instead. This is the descriptor that I have maintained since. ${ }^{6}$ Thirdly, the most obvious reason for the ineffectiveness of using posters to recruit is that I only received ethics clearance to begin recruitment a few weeks before the seven-week long, city-wide transit strike. The City of Ottawa had no bus or O-Train service for this duration during the coldest time of the year. For this reason, the community at large and the marginalized in particular were relatively stranded. I met with various community service providers and they were astounded at how slow business was and told me not to bother putting up posters until after the strike. The inaccessibility of community resources was well reported throughout

\footnotetext{
${ }^{6}$ The term 'living in poverty' may be as accurate as 'economically disadvantaged' in many cases, but it is a much more powerful phrase that can invoke the stigma of poverty. The second term, 'economically disadvantaged' is somewhat less personal and speaks more to the impacts of poverty. It is possible that my initial use of 'living in poverty' was not welcoming to participants.
} 
the strike (Casey, 2009: 3); however, “The Well”, a women's drop-in centre in downtown Ottawa, heard about my project and invited me to attend their monthly senior's lunch. These lunches are open to any 'senior' women in the community. There were less than a dozen women present when I attended and since the definition of "senior" used by "The Well" differed from mine, I was not able to find any recruits. After nine months of recruitment, I found participants through five personal contacts. Those participants snowballed ${ }^{7}$ into a total of nine. In the end, I was only able to use eight of the urban interviews as one participant refused to sign a consent form.

The recruitment process for the rural participants was a vastly different experience. I have one personal contact in the upper Ottawa Valley who gave me 12 contacts within a few short days. My contact recruited participants through her church and her longstanding connections in the area. The rural recruitment process speaks to the importance of social networks in rural settings, a phenomenon expressed through previous research that I explore further below (Shenk, 1998; Scott, 1998; Cranswick and Thomas, 2005). Comparatively, this process also demonstrated one of the major problems with urban recruitment - lack of trust. My rural interviewees were recruited quickly because my contact already had an established relationship with each participant and was able to vouch for me as a researcher before the interviews began. There was an element of trust present that was not so readily available for the urban interviewees. For the rural portion of my study, I was able to identify nine willing and eligible women.

\footnotetext{
${ }^{7}$ Snowball recruitment is a method of recruitment often used for hard-to-reach or hidden populations that entails recruiting a small sample of individuals and asking them to recruit other individuals within their networks (Heckathorn, 2011).
} 


\section{$\underline{\text { Interview Process }}$}

A total of 17 interviews were conducted between January and July 2009. As mentioned, the interviews were semi-structured and varied between thirty minutes and four hours with the average interview lasting about an hour. All were held in the homes of the participants with the exception of one interview conducted in a local restaurant. All interviews were audio-recorded with the exception of one. In keeping with feminist research methods, all women were mailed a copy of their transcripts and given the opportunity to make any changes, should they feel that the transcript did not adequately represent our conversation. The women were each given the opportunity to choose pseudonyms. ${ }^{8}$ In addition, each participant was also offered a copy of the final project. This was important for demonstrating that while their experiences might seem mundane to them, their stories represented legitimate knowledge. The research participants in my project were well equipped to present an accurate image of the reality of experiencing economic disadvantage.

I approached each interview with a loosely structured list of themes and general questions. Each interview began with a discussion of basic personal information, including mother tongue. The most common mother tongue languages were English in the urban areas and German in the rural areas. Three participants identified French as their mother tongue. Being a franco-ontarienne myself, these interviews jumped faster to familiarity than the others because we were able to bond immediately over our common experience of being a linguistic and cultural minority in a province in which that identity is contested. One of the interviews was conducted solely in French and it was also the

\footnotetext{
${ }^{8}$ All names listed within this thesis are the pseudonyms chosen by the women themselves.
} 
only interview where the participant refused to be audio recorded. Although I never probed her for a justification, it became clear throughout the interview process that Simone was incredibly private about her experiences of hardship. Although there are many French speakers in the city of Ottawa, the franco-ontarienne community is relatively small. I suspect that her reasons for wanting the interview to remain "off the record" were borne from her desire to maintain her privacy.

The process of interviewing Simone was a reminder of the power dynamics within the interviewing process. Although I entered her home as an educated researcher, the power balance quickly shifted to a more egalitarian one as we shared in our experiences of being franco-ontarienne women in urban Ottawa. This conversation did more than simply "break the ice"; it established a commonality that helped bridge the space between researcher and participant. While I interviewed another participant at a later point that I knew from my personal life, the familiarity we had did not compare to the relationship between Simone and myself. The sharing of a common struggle was indispensable in redressing the power imbalance between researcher and research participant.

The second element of basic information that I asked of the participants at the beginning of the interview was their age. Were I to do a similar project in the future, I would not begin by asking for the participant's age. One's name and age were the very first questions posed and although the women were chosen based on their age and economic status, these were the two most sensitive topics for them. In contemporary Canadian society, a woman's worth is closely linked to age, which is one of the primary reasons for their marginalization as elderly women (Bluhm, 2000). Therefore, beginning 
with a person's age might seem innocuous initially but it was clearly invasive for many. After asking for the participant's name, age and mother tongue, I then started off with basic questions regarding their location, history of living arrangements, etc. This was followed by questions in the 'economics' category of work history, means of income, economic history, etc. No questions were asked regarding amount of income or assets as my project is more concerned with subjective rather than objective poverty. My interviews aimed to understand life on a tight budget, something that did not necessarily require fixed numbers. The final questions clustered around the social lives of each participant, their friends, relationships, hobbies or activities. I ended each interview by asking participants if they had any recommendations for how to change their situation and/or the situation of others in regards to being elderly and economically disadvantaged.

The interviews varied according to personality but most were informal and involved intermissions for refreshments and the perusing of pictures and family albums. In every case, the researcher / participant relationship had clearly changed by the end of the interview. Initial formal greetings and "hellos" and a possible handshake often ended with hugs and a "come by again soon". My experience interviewing elderly women was very much in line with the work of Kestin van den Hoonaard, whose research focuses on the experiences of elderly widows (2005). Her experience conducting interviews about widowhood led her to focus specifically on the methodological implications of interviewing elderly women. Kestin van den Hoonaard's observations were that elderly women are self-conscious and want to "get it right" so they employ a number of tactics to check in with the researcher to ensure they are on the right track. Although implicit, the 
women are aware of the power dynamics and often make the interview process a social one so that they are not necessarily a subject of research but rather a hostess.

Van den Hoonaard's experience very much mirrors my own. After each interview, I encouraged participants to contact me at any time if they wanted to be removed from the project, wanted to add something to their interview or were simply in need of a ride or some company. None of the participants wished to be removed but a few of the participants did make further contact to include some missed details and/or to socialize. I have maintained a friendship with many of the women. Sharlene Nagy HesseBiber reflected on her experience of conducting feminist research and defined it as such:

Research that gets at an understanding of women's lives and those of other oppressed groups, research that promotes social justice and social change, and research that is mindful of the researcher-researched relationship and the power and authority imbued in the researcher's role are some of the issues that engage the feminist researcher. (Hesse-Biber, 2007: 117, emphasis hers)

Throughout the research and analysis process, I worked to centre the voices of the participants over my own and to practice continuous self-reflection to ensure that the research conclusions accurately represented the women's lives.

Finally, it is worth noting that I conducted each interview with elder abuse resources on hand. For ethical reasons, I researched the elder abuse disclosure protocol that stated that if a participant did disclose abuse, I did not legally need to disclose the information because the participants were over the age of 18 and not in the care of a service provider. No incidents of elder abuse were disclosed or discussed. 


\section{Data Analysis}

Although the research question lends itself to an urban/rural divide, the data presented itself more thematically. The women's experiences were fundamentally similar but contextually different. Therefore, in transcribing the interviews, coding software was used to assemble similar ideas and experiences. Once all of the interviews were transcribed, themes began to appear. I used the coding software NVivo and the mapping software MindMap to synthesize the extensive data and align similar themes. I used NVivo to establish patterns in the interview transcripts and then used MindMap to visually map out the most effective means of connecting the various subject areas into cohesive chapter outlines. The following chapters present and analyze the major themes gleaned from the 17 interviews. 


\section{Chapter Four}

\section{"Life sure has its challenges, but somehow we get through it": Resourcefulness and $\underline{\text { Resilience }}$}

Long before I began analyzing the results of the qualitative interviews, I sensed the emergence of a common theme. During the interviews, participants responded to a series of questions regarding their daily experiences of being economically disadvantaged and elderly. Questions of "resourcefulness" and "resilience" were not probed in the interviews nor explicitly defined by the interviewees and they did not appear consciously aware of the importance of it in their lives. However, the theme of resourcefulness was a major part of every interview. This was made all the more apparent when I found myself into an embarrassing situation during one particular interview.

I interviewed Lynn at her home in rural Eganville during the dead of winter. We had a pleasant interview, which included lots of tea and looking at family photos for a few hours. Although it was a sunny day, it had stormed most of the week and so I left her house by way of a driveway covered in black ice. In trying to head to my next destination, my car got stuck in her long driveway a total of three times. I was not only completely mortified but completely unprepared as well. Having dressed for an interview inside and not for outside winter weather, I was knee deep in a snow bank, attempting to dig my car out of the ditch. I looked up to see Lynn coming up the driveway with soccer cleats on her feet and a bucket of ashes. Realizing I needed more than some grip for my tires, she called a relative who lived up the road and had him come down with a tractor. He was able to pull me out of the ditch successfully and instruct me on how to drive 
safely to the dry road. I was dumbstruck with humiliation and gratitude and only when I had safely made it to my next stop did the significance of the situation dawned on me. I had been looking for keywords and themes in my interview, and yet here I was, experiencing resourcefulness and resilience in action. In making one phone call, a sequence of events was set into motion and before I knew it, people were coming to my rescue, no questions asked. I had gotten myself into a pretty serious predicament and was able to get out of it in a short period of time without the help of police, tow trucks or any formal service. This experience became the metaphor for my research and, in particular, this chapter.

Once I began sorting through the actual data, the theme of resourcefulness and resilience became even more apparent. I define resilience "as the capacity to remain well, recover, or even thrive in the face of adversity" (Hardy, Concato and Gill, 2004: 257). The women interviewed used creativity and resilience to help them "get by" in a variety of ways. Their resourcefulness is not only a survival strategy; it is a source of pride and a value they cherish. The types of resources they created and relied on varied but primarily fell into one of two categories. "Formal services" consisted of institutionalized, subsidized and/or formally organized services offered by the municipality, the Victorian Order of Nurses (VON) or a local community centre, for example. Those services are recognized as "institutionalized" or "formalized" by their organizational structure, sources of funding and recognition by the community. The second are "informal services" which is a term I use to define the informal networks that the participants rely on when "formal" services are unavailable, inadequate or inaccessible. "Informal services" consist of grassroots organized, self-created networks often formed intuitively 
by the participants in the absence of more formalized services. Thus, this chapter explores the demonstrated resourcefulness of the participants by first describing their experiences with formal services, followed by a demonstration of how they use informal resources to "get by" when formal services are problematic. The use of informal services and networks, organized by the participants themselves, played a major role in the lives of the women and was by far the most prominent theme of each interview. Although many of the women lived lives of immense hardship, their tenacity and creative thinking helped them survive. When faced with adversity, they were able to persevere thanks to their resilient spirit and ingenuity. Their resilience can be seen through their use, creation and management of formal and informal services. When sifting through the data, there were innumerable examples of the participants using their resourcefulness to overcome adversity. Throughout the interviews, resilience and resourcefulness clustered around three issues: transportation; health; and care. Focusing on these issues, I next outline the myriad ways in which the participants survive and discuss the importance of negotiating both formal and informal services.

\section{From Point A to Point B: Transportation}

Using semi-structured interviews as outlined in chapter three, I entered each interview with a brief outline of questions and topics on which I wanted to focus. None of the questions specifically related to resources, either accessed or desired, and yet each interview pivoted around discussions of resources and networks. The interviews conducted with urban women living in the city of Ottawa focused more heavily on formal 
resources presumably because of the strike by public transit workers. ${ }^{9}$ As previously mentioned, I received ethics clearance mere weeks before the transit strike began and so finding urban participants was difficult. The participants I did find were very concerned about the transit strike. In fact, even the interviews that I conducted after the transit strike included discussions about how the strike had deeply affected either themselves or those they knew. The transit strike was also a topic discussed by the rural participants, who do not have transit access but still felt the effects either from family and friends in the city or who were affected simply by the stories in the news.

The transit strike, therefore, became a major component of the interviews. It obviously affected the entire city, but was particularly problematic for those who had limited mobility or resources such as the elderly, disabled, lone parents and the economically disadvantaged. Many of the women spoke highly of public transit in general and saw it as one of the major positives of living in the city:

[...] I've always traveled by bus, I don't mind. I had a car but I don't like driving now because there are too many crazies on the road, so I got rid of my car ... about seven years ago, but I take the bus everywhere. And this is what I like about the bus. You can get a bus to get you everywhere. If I don't know what bus to take, I call OC Transpo [Ottawa City Transit] and they tell me the best buses to take. (Margaret)

The issue of transportation was particularly relevant for the participants due to the timing of the interviews. Yet, transportation and the importance of access appeared to be a core matter that went beyond the immediate concerns of the strike. For Margaret, the availability of public transit was a relief from the stresses of driving whereas Lorraine,

\footnotetext{
${ }^{9}$ The city of Ottawa's transit strike began on December 10, 2008 and officially halted all public transportation, including buses and light-rail. The strike officially ended 52 days later; however, the actual end of the strike was not so evident since it took many weeks for all routes and services to return to full service.
} 
another participant, saw public transit as the lifeline that enabled her to leave her apartment. Transportation is an obvious link to the outside world for elderly women, particularly those who live alone, as was the case for 14 of the 17 women I interviewed. Most had been divorced or widowed for many years and relied on public transportation for daily necessities and social interaction. Similar research conducted with economically disadvantaged elderly women has found that transportation is an important, yet often over looked issue. Although Barusch did not specifically ask any questions regarding transportation, "over half (52\%) of the women [she] interviewed spontaneously mentioned the topic. $[\ldots]$ The most often-mentioned category on this subject related to problems associated with lack of transportation. These included inability to shop for better food prices, inability to take advantage of government commodities, inability to vote, difficulty getting to a job interview, and (most often) isolation. [...]" (1994: 57).

Susanne, an elderly woman from urban Ottawa who routinely used public transportation after she had to give up her car for financial reasons, expressed frustration regarding the public transit system in Ottawa. She was often concerned about the ability to even get to the bus stop, assuming there were buses running. She spoke of the difficulty in walking to the stop in the winter, as the pathways were rarely cleared and it was nearly impossible to carry grocery bags:

[...] even if they get the parking lot [plowed] and so on here, and it's sometimes a couple of days before that's done, it's the pathways, the walkways are cleared but they're not done well enough when your footing isn't good. You know? It's okay in that it may be plowed but it's so uneven and then it freezes and its icy lumps and when your footing's not good, you can't really walk on it. So even though it's just over there, it might as well be 10 miles away. [...] So it's just, sometimes, although it looks like it should be nothing, those are little hindrances that are hard with limited balance and mobility. That would seem like nothing, you know, to a 12 year old or whatever. (Susanne) 
All of this is moot, of course, during a 52-day transit strike. Nonetheless, it is incorrect to assume that having a public transit system is enough. As stories like Susanne's demonstrate, the elderly have specific transportation needs that must be considered in the creation and maintenance of an accessible bus system: "Older people (aged 60 and over) commonly experience transport disadvantage, including substantial problems with bus usability, which limits their participation in society and results in poorer health outcomes" (Broome et al., 2010: 435). Other research calls for the recognition of the special needs of the elderly, such as more frequent bus stops, speedy plowing and de-icing of pathways and specific training for bus operators (Ibid.). The World Health Organization recognizes age-friendly public transit as an important part of a functioning and accessible city (WHO, 2007).

Transportation is an important area of study when examining the lives of the elderly because it not only speaks to issues of mobility and access to resources but also to independence. More specifically, transportation (or lack thereof) is a large determinant for housing. As we age, our residential needs change. Whether it is the arrival of children requiring more space or the loss of mobility requiring adapted living arrangements, our housing needs change as we do. Our choice of living arrangement is greatly dependent on proximity to resources and, in turn, access to transportation. If you are mobile enough to take care of your daily needs, for example, but have no access to transportation of any kind, then your capacity to live independently in your own home has been greatly reduced. Nonetheless, remaining in their home as they age is often listed as a top priority for the elderly (Wanless, Mitchell and Wister, 2010; Morita, Takano, Nakamura, Kizuki and Seino, 2009). A promising trend in this regard is a move towards "aging in place". It 
is defined as "an approach to elder care service delivery that takes place outside of an institutional setting and allows elders to stay in their own homes" (Bookman, 2008: 422). And remaining in place is something the elderly have clearly been doing, as most Canadian elders aged 65 and over lived in private households in 2006-91\% of women and 95\% of men” (Milan and Vézina, 2011: 12).

In Ottawa, Aging in Place is a formal program through Ottawa's Community Care Access Centre located in apartment buildings across the city. The program enables elderly residents to remain in their own home by providing them with an important lifeline should they require support. One of my urban participants lived in an Aging in Place residence in downtown Ottawa and her experience speaks to the importance of formal services in enabling transportation and, in turn, a life of independence. Lorraine had acute health problems that included severe respiratory issues. She lived in downtown Ottawa and therefore technically had access to the public transit system, but because of her ill health, was not able to take advantage of it. Thankfully, Lorraine lived in an Aging in Place building; the worker in the building noted her isolation and she was set up with The Good Companions, a local centre for the elderly. The Good Companions employ a driving service where local volunteers drive elders-in-need to do errands and attend medical appointments. In Lorraine's case, her ability to live independently came as a direct result of a formalized service in her apartment building. When the public transit system failed her because of her health problems, the existence of an Aging in Place program in her building connected her to another formal service in the community to ensure her needs were met. 
Another urban participant named Marie did not have the same luck. However, her creative resourcefulness is an excellent example of the inventiveness I witnessed so often in this project. Marie was an urban participant who lived alone in an apartment building comprised solely of low-income elders. Like most dwellings that are inhabited mainly by elders, it had a high proportion of female occupants. Scheduling an interview with Marie proved difficult because she maintained an unbelievably hectic schedule. When we finally did meet, I asked her about her busy timetable: "Yeah, the association here, I'm the treasurer. And we have parties we organize, we have bingos, we have sandbags and parties and cards; we do all kinds of things. [...] No time to be lonesome." Her calendar was filled with activities that ranged from social outings to fundraisers for local charities. She hoped to keep her neighbours active and engaged, while also being passionate about giving back to her community. She spent 15 years working with a local organization supporting families with Cystic Fibrosis and helping to fundraise for the local children's hospital. It was clear that being social and connected to her community was an important part of Marie's strategy for staving off loneliness and maintaining a link to the outside world. There is a well-established link between rich social networks and quality of life (Morita, Takano, Nakamura, Kizuki and Seino, 2010) and, in the case of Marie, her social networks helped her through difficult situations. Marie participated in my project during the bus strike. Being an urban participant, the issue of transit came up early on and when asked if she had been affected, Marie responded:

Yeah, it didn't affect us. Well, it did in a way, but not like yourself; someone who takes the bus everyday to go to work. One of my granddaughters had to walk for an hour before she got to work. That's inconvenient. I didn't have any. 
Her refusal to acknowledge any hardship in her life was a common occurrence I witnessed with several participants. There was a concerted effort by many to minimize the hardship they had experienced and, in many cases, continue to experience. Their reasons for being unwilling to divulge the difficulties in their lives can be attributed to many things, including shame, a desire for privacy and stoicism. In the case of this project, it is also possible that this unwillingness to speak frankly about hardship was compounded by the age difference between the participants and researcher. G. Clare Wenger wrote about her experiences interviewing elderly women and her conclusion was that in order to have the most success, the interviewer should be a middle-aged woman (Wenger, 2001). In my case, although gender may have advantaged my interview process, there were clear power dynamics between myself as a researcher in my early 20 s working with participants who were all over the age of 65. This became clear in Marie's interview when she repeatedly diminished her experiences of hardship. It often took several follow-up questions in order to get a more realistic picture of her reality. In regards to transportation, she acknowledged that the transit strike was difficult for others but downplayed how it impacted her. When I followed up to ask her how she managed to get around without access to public transit, she divulged that she and other neighbours were left with very few options. However, they did not dwell on their bad luck. Instead, relying on her strong familial networks in the community, she found some single men in the apartment building that had access to vehicles. Anyone in her building that needed a ride could pay these men some gas money for a ride to wherever they needed to go. Marie and her neighbours were not able to rely on formal services in light of the bus strike but because of the strong informal networks they had maintained over the years, 
they were able to come together to create an informal system of transportation and, in turn, find a solution.

This reliance on informal networks to "get by" in moments of adversity was also seen in Susanne's story. Susanne was one of the youngest women I interviewed and struggled with being both economically disadvantaged and disabled. Her options were limited not only by her mobility but also by her income since she had been living on a fixed income from the Ontario Disability Support Program before she transitioned to Old Age Security. When I asked her how she had been impacted by the transit strike, she responded with an emphatic "yes":

It affected a lot of people, neighbours and so on, and it would have [affected me] more if I didn't have my friend Frank who is helping me out and so on. Some people, like Tina, had forms to fill out and all that sorta stuff because she was off work with back problems. (Susanne)

Susanne had limited options based on her age, disability and income but because of her strong connections in the community, she was able to troubleshoot an effective solution. In addressing the question of how she negotiated a lack of transportation in light of the strike, Susanne's approach was similar to Marie's. It took some probing for her to acknowledge that she was affected and her immediate response was to state how she was not nearly as affected as people she knew. Nonetheless, the transit strike placed her at a disadvantage and it was only through reliance on her strong community networks that she was able to reflect back on the strike and feel as though she was not disadvantaged.

Susanne's analysis of her situation was similar to the perspective of other elderly participants interviewed in Kestin van den Hoonaard's project. She observed that when interviewing elderly women, they often question the strength of their answers or 
downplay the importance of their experiences (2005). Regardless, Susanne's experience was clearly representative of a common occurrence for elderly women in Ottawa. Her story was another example of the resilience of elderly women who navigate gaps in formally organized transportation by relying on their strong familial and social networks.

\section{Health Strategies: Food for Thought}

One of the advantages of conducting semi-structured qualitative interviews is the liberty it gives respondents. By asking open-ended questions, participants enjoy the flexibility to speak to their interpretation of the query. At no point in my formal interviewing did I ask the participants to discuss food security, cooking routines or cuisine. I also did not ask them about their health status or level of ability. Yet, when asked to discuss their overall economic status, every participant mentioned the impact of rising food costs and several participants discussed at length how they were forced to think strategically about health issues. Throughout my interviews, it was evident that food security and overall physical health were a concern for them and that we could not discuss their economic reality without inclusion of these issues. All of the participants brought up rising food costs and food insecurity as a reality in their lives. Their experiences reflect a growing trend across the country. Food bank usage in Canada has risen $39.9 \%$ over the past decade or so with $44.6 \%$ of users being women (HungerCount, 2012: 24). When broken down into the rural and urban divide, food bank usage for the elderly is almost at par (Ibid). Rising food costs, limited mobility to shop for better prices and increased health needs exacerbate the situation for the elderly. Living on an already limited income meant that additional funds could not be found to fill the gap. In some 
cases, the women sought out help from formal services but more often than not, they simply changed their shopping habits or cooked creatively.

In this section, I begin by discussing food security followed by outlining specific health strategies undertaken by some of the participants. In both cases, I argue that formal networks are important but gaps exist and, when they do, it is the existence of tight informal networks that allowed the women to overcome negative circumstances.

Vera was a rural woman who had lived on a farm most of her life. For much of her life, she and her husband had a large garden and therefore purchased limited groceries. They were able to keep their food costs down by living off the land they owned:

We only bought what was needed. Well, we grew our vegetables, potatoes and did a lot of canning. Had our own pork and beef. We didn't spend much on food and that kinda carries on. You kinda keep living like that. [...] We had our own smoked sausage and pork sausage. Now we don't make it anymore. (Vera)

With her husband's death and her declining health and mobility, Vera was no longer able to operate the smokehouse or head to the strawberry fields to pick berries for canning. Since she had lived in the same area her entire life, she had built up strong social capital in her community and it was these connections that helped her strategize. Although she now lacked the mobility for some tasks, she was able to maintain her family's tradition of making sauerkraut, which she fermented inside her house. The sauerkraut provided sustenance throughout the winter, maintained her family tradition and allowed her to cut costs as it was relatively inexpensive to produce. She would then share some with her neighbours and friends, trading her sauerkraut for preserves that they made. This informal bartering system allowed Vera and her neighbours to reduce the impact of rising food costs while also creating an opportunity for them to maintain family traditions and 
recipes. It was clear in talking to Vera that her keeping up her family tradition of sauerkraut was an important source of pride.

Susanne, an urban participant, also discussed another strategy Vera employed. Both Vera and Susanne spoke about the benefits of buying food in bulk. Buying food and food supplies in larger quantities was not only less expense in the long term, it also provided an opportunity for communal sharing. In Vera's case, she would purchase food in bulk and freeze portions to preserve it. She was able to do so because she had access to a large freezer. Susanne lived in a small, urban townhouse and did not have a large kitchen or a deep freezer, so her capacity to freeze food was limited. However, she and her neighbours purchased in bulk as a means of assisting each other:

What we do, a lot of the time, and I'm fortunate because if you were more isolated you wouldn't have that, is if they got, sometimes it'll be 2 bags of potatoes for a $1.49 \$$ or whatever it is, so we'll buy and share. I mean there is a program around, too the 'Good Food Box'. I've never tried it and so on, but maybe it would work if you have an entire family but we do it by shopping where the sale is and dividing up our stuff. (Susanne)

Susanne and her neighbours knew of a community resource that would provide a similar service, but they felt it was better suited for large families, rather than individuals. Therefore, they devised a system where they would assist each other instead. Their communal 'Good Food Box' went a step further with sharing of prepared meals:

It depends on the time of year, but somebody makes a macaroni or soup, we do that a lot. It's sorta like a stone soup. One of the girls is really good at making soup but she doesn't always have the ingredients, so we might give her whatever and then she produces it. And sometimes, they'll be a knock at the door and somebody hands me a little dish of spaghetti sauce because this one over there is making a big batch and so on and so forth. So we sort of divvy up. (Susanne) 
Only one participant relied solely on formal services for food security. Sylvie, a rural participant, had limited vision and mobility and was no longer able to prepare her own meals safely. Being a longtime resident and volunteer in her community, she knew of available services to assist her and settled on the Victorian Order of Nurses (VON) food service. For less than the cost of making her meals at home, Sylvie was able to pre-order frozen entrées and simply heat them in the microwave when she was hungry. For Sylvie, this meant that she could continue to live independently and because it was a service that required a fee, she did not feel as though she was using a service that was reserved for the "less fortunate". Living independently was about more than simply meeting one's daily needs for survival without assistance. Reciprocity was an important element of how they negotiated services and, in Sylvie's case, because she was paying for support from VON, she was comfortable with the arrangement. Not being mobile enough to be barter anything else in exchange, Sylvie relied on formal services that required only the exchange of a fee. Had she relied on an informal network of friends or family, she would have felt indebted to them for having nothing to give in exchange other than gratitude.

Altering their cooking and shopping habits is one way in which the women were able to stretch their inadequate incomes to address the shortfall created by rising food costs and their increasingly limited mobility. When this proved impossible, they relied on formal services to fill that gap. Their creative strategies proved effective at ensuring they had access to satisfactory sustenance. However, there is less capacity for creativity when it comes to meeting one's health and care needs. Cutting corners to meet your health needs can be incredibly dangerous and harmful to your long-term health. Equally as important as meeting your physical health needs is the need for overall care and 
companionship. Care is essential but not without contention. Nonetheless, the women proved effective at finding creative strategies to ensure holistic care. The following section profiles the ways in which my 17 research participants strategized to meet their care needs, both physical and emotional.

"I get by with a little help from my friends": Care

Susanne, an urban participant, had been dealing with a multitude of health problems for several years. When she transitioned from the Ontario Disability Support Plan (ODSP) to Old Age Security (OAS), she felt that being disabled had put her at an advantage because she was used to living on a fixed income. She had built up a host of strategies for addressing the gaps between what government subsidies paid for and what needed to be paid for out-of-pocket. Susanne's health problems included diabetes, which was improved significantly through the intake of supplements. However, since supplements are not covered under OAS in the same way as prescriptions, she could not afford them. In turn, her health deteriorated. Knowing that the supplements improved her health but lacking the funds to purchase them, Susanne began asking for them in exchange of Christmas and birthday presents from family and friends. This not only meant that she was able to access the much-needed supplements, but receiving them as actual gifts rather than gifts of money meant that she did not need to claim the gifts as income. Susanne was able to circumvent the gap in her health care by creatively relying on family and friends.

Relying on one's support networks to help you purchase supplements is a creative means of making one's health needs. There are times, however, when shortcuts can have 
detrimental health effects. In discussing the ways in which she is forced to be resourceful to make ends meet, one particular example from Susanne stood out:

[...] my needles are somewhere around $\$ 38$ for a box of needles. Well I don't change my needles all the time. I change when my vial runs out instead of each time, so that's one way [I save money].

Susanne knew that reusing needles was unhealthy and put her at risk of infection; however, her need to stretch her resources as far as they could go outweighed her health concerns. I was struck by this particular example. Witnessing an elderly woman reusing diabetic needles in order to save money is a distressing reminder that we cannot simply celebrate the resourcefulness of these women; we must also recognize the difficult conditions that require so much resourcefulness in the first place.

I begin with Susanne's story because it highlights the complexity of care. Susanne's health needs required tangible, practical solutions. She needed to take her insulin but could not afford a daily needle exchange. She needed to take supplements, but could not afford to purchase them. Although her experience reads as extreme, it is the physical manifestation of a common reality for many other women in this project. The need for physical and emotional care is a fact of human existence but it is far from straightforward. The very definition of "care" is questioned by academics in various disciplines, particularly in feminist studies and disability studies. To best understand the ways in which the participants in my project navigated care, it is important to examine how care is debated in various disciplines.

Care is an essential concept in both feminist studies and disability studies, yet it is understood in distinct and often oppositional terms: "Where feminists see care in terms of its role in the making of men and women, disability activists see it primarily in terms 
of the infantalization and disempowerment of disabled people" (Hughes, McKie, Hopkins and Watson, 2005: 261). Feminists have offered various critiques of the gendered nature of care and, in particular, how carework is primarily occupied by women and, therefore, undervalued and underpaid (Armstrong, Armstrong, Scott-Dixon, 2008). Feminist scholars have challenged the gender essentialist argument that carework is inherently a women's responsibility and, as such, requires no societal compensation or recognition (Hughes, McKie, Hopkins and Watson, 2005). At the same time, certain elements of "feminist work on care emphasizes need, emotion and embodiment," in particular, the need to recognize that those providing care are human beings with complex emotions and responses (Ibid: 271).

From a disability perspective, the focus shifts to the person receiving care and the ways in which people with disabilities are typically framed as helpless and dependant. From this perspective, the term "care" is highly contested and, in some cases, outrightly rejected. The label of care is so profoundly wrapped up in connotations of institutionalization, infantilization and disempowerment that they have shifted to terms such as "personal assistance, help or support" (Ibid: 261; Kelly, 2012: 14). This framing is reflected in the Independent Living Movement, which places an emphasis on "autonomous decision-making" and frames people with disabilities as the employers of care attendants (Kelly, 10-11).

It is clear that tensions exist between the feminist understanding of care and the framing of care by disability scholars. The critique of feminist work in this area is that in attempting to value carework, it erases the experiences of those being cared for. This model, therefore, fails to challenge a patronizing understanding of people with 
disabilities, the elderly, children, etc. The very fact of organizing people with disabilities with the elderly and with children speaks to this critique. Simultaneously, by rejecting the term care, as is often done by people with disabilities and disability scholars, there is a failure to recognize the emotions involved in caring for another. To simply reduce the caretaker and care recipient relationship as transactional not only highlights the capitalist underpinning of this framework but also creates a false dichotomy. Care recipients are defined as either entirely dependent or entirely independent, a caregiver as either a distant employer or emotionally invested friend. For this project, I subscribe to Christine Kelly's call for a nuanced and complex understanding of care. She suggests that care "is an unstable tension among emotions, actions, and values, simultaneously pulled toward both empowerment and coercion" (7). As elderly women, my participants' lives intersect with the insights from feminist and disability studies. Their reality of seeking and giving care is clearly gendered, while their position as elderly people means they are more likely to require care on a consistent basis. Furthermore, their position as economically disadvantaged elderly women means their ability to access resources for care is significantly more difficult. As I will illustrate through a few key examples, the women navigated the complexity of care relationships by adhering to a strict policy of reciprocity.

I interviewed Anna-Louise on a blistery winter afternoon. She was incredibly hospitable and offered me tea and leftover Christmas cookies. Her interview was informal and conversational. She spoke very candidly about the joys and struggles of her life and had an impeccable memory for detail. Anna-Louise lived on a farm in the same rural area where she had been born and raised. Across the road lived her dearest friend, 
Vera, who had also lived in the area her entire life. In fact, Vera joked at one point in the interview that she was in her 20s before she realized there was a world outside her community: "When I was growing up, I didn't know if the world carried on out there or if the world dropped off after here!" As rural elderly women living alone in a fairly isolated corner of their community, Anna-Louise and Vera were vulnerable. In order to ensure their safety and wellbeing, the women relied on their strong friendship and familial bonds to protect each other. They did this by devising what is traditionally understood as a buddy system. At 11 am and $4 \mathrm{pm}$ every day, Anna-Louise and Vera would call each other. If someone did not pick up the telephone right away, the other would wait ten minutes and then try again. If they still had no luck, then they would call the police to come and check on them. Their strategy was effective and completely informal. As the women aged and the need for checking-in increased, it was obvious that they would rely on each other rather than engaging a formal service. Formalized services existed in their community, including a similar check-in service, but Anna-Louise and Vera never even considered using it. From their perspective, formalized services existed for those who were completely isolated with no assistance from friends or family.

Anna-Louise and Vera's buddy system was striking for many reasons, including the way in which the story was shared. Both women mentioned the system in passing and only when questions of isolation and social time were raised. Although they had devised an ingenious system with the dual purpose of ensuring safety and staving off isolation, in their minds, it was the most obvious thing to do. Their solution speaks to several important trends that were seen throughout several of my interviews. First, the use of informal services as a means of resilience is evident in this example. Rather than accept 
that aging women could not live alone or at the very least, could not live without outside assistance, the women banded together to create a system that was both effective in its immediate outcome but also effective in alleviating concerns from family members. Secondly, the buddy system was one they were comfortable with because it involved reciprocity. Anna-Louise did not owe Vera or vice versa. They relied on each other in equal measure. In her qualitative research with elderly women in the United States, Amanda Barusch observed that "[r]reciprocity, or past help, is one of several conditions under which help can be given without loss of face" (60). Lastly, Anna-Louise and Vera's system, and subsequent justification of it, spoke to the rejection of formalized services under the belief that they were reserved for the "truly hard-up."

Sylvie, another research participant, expressed this same sentiment. Sylvie was also a rural woman who lived alone. Although she had limited mobility and a visual impairment, she was very active in her community and at 84 was featured in the local paper for her work teaching other elders how to use computers. Sylvie also sang in a local choir. When I asked her to elaborate on her time in the choir, she said that they met every Monday and then travelled:

Yeah, seniors' homes. It's amazing. It's wonderful and you go in there and you see the pleasure they get out of what we are doing. The singing that we do, let me show you here, my songbook. (Shows me songbook) It's pretty much songs that were, you know, that older people can relate to.

Sylvie was an elderly woman with mobility issues who lived alone in a rural area and who volunteered her time to entertain other elderly people living in retirement homes. For her perspective, there was no one in dire circumstances more than people who lived in retirement facilities. To her, and to other participants, those who lived in retirement 
facilities were people to be pitied; their lives were unenviable. Even though a retirement facility meant three meals a day, planned social activities and the security of having staff at your disposal, for all the women I spoke with, a retirement facility was the place where those without decent loved ones went to die. This perspective speaks to the issue of reciprocity in the care relationship. Furthermore, it speaks to the way in which the participants straddled the feminist and disability studies' definition of care. The women felt that receiving care was only possible if you were also in a position to care for others. They framed care as a reciprocal relationship that always contained a human element, regardless of the nature of the task. Above all, the women I interviewed spoke about their experiences of being cared for by others and vice versa without ever referring to it as care. They felt that taking care of your friends and ensuring that you were taken care of so as not to worry your family, were moral obligations and non-negotiable. Many participants indicated that they had not even thought about this element of their life until it came up in the interview.

Although the women downplayed the significance of their care networks within their own lives, those relationships gave valuable insight into their resilience and resourcefulness. When faced with adversity in the form of transportation gaps, rising food costs or the needs of an aging body and aging home, the women consistently found creative solutions. Whether by devising informal systems or by relying on assistance from friends, each interview demonstrated their strength and tenacity. However, "[e]ven as we admire women whose strength and creativity has enabled them to not only endure but to enjoy life, we must reject the conditions that burden their days and sap their energy" (Barusch, 191). In the following chapter, I will examine how our current 
understandings of poverty and social assistance have created an unjust system where elderly women are systemically disadvantaged. 


\section{Chapter Five}

\section{"So to say I have an easy time? I don't": The Limitations of Resilience}

When I interviewed Arctic, she had just celebrated her $66^{\text {th }}$ birthday and her recent move to a remote part of Ottawa. Self-described as "an urbanite my whole life," she was still adjusting to her new somewhat rural life. Arctic was one of the few participants with formal post-secondary education. On a whim, she thought she would throw her hat into a competitive job application process for a prestigious private sector business. To her surprise, the rigorous application process was successful and she was chosen. The job had "all the perks" with a competitive wage and full health benefits. Unfortunately, her plans were derailed:

I was with them, I don't think I was with them for a year and I just, I just collapsed. In retrospect, I could see it coming, you know. I could see how things were leading up to that. At the time, I had young kids, I was a single parent, why wouldn't I be tired? So I just pushed myself on, I had no other choice, really. I couldn't stay home. I was divorced and the kids, they were a handful because we didn't know our son was autistic but we just knew something was wrong. Nobody knew; there was no help for that. (Arctic)

Blaming her exhaustion on her inability to balance work and life, Arctic finally reached a breaking point and sought help from her physician. She was sent to another physician who said she was exhausted and needed to take a few weeks of for bed rest. After weeks of bed rest, however, she emerged further exhausted. Her physical health deteriorated significantly but a diagnosis was difficult to find. It took five years for Arctic to be diagnosed but that changed very little. With no cure and few options to manage her symptoms, she had to accept that her new condition would define her life moving 
forward. While she struggled with having to give up her career and managing her physical symptoms, Arctic was still raising her children and dealing with her son's increasingly troubling behavioral issues. During this time, Arctic met a new partner who was supportive and understanding, but stress came soon after when her partner's private business had to file for bankruptcy, leaving them in financial ruin. Looking back on her life since her illness, Arctic was candid in describing her anguish:

This has been the issue with me, all along. There have been times that I thought 'I just want to die.' When my kids were younger, I wanted to live for them because it would have been hard for them. And now, it's still. My kids tell me I'm so important to them, but I don't feel important to them! [...] There's lots of times where I think 'What kind of life is this?'

She went on to share one of the most difficult stories I heard throughout my research. In discussing her current situation, she spoke affectionately of her partner who continued to work while serving as her primary caretaker. It was evident that her partner not only assisted her in her physical needs but her emotional needs as well. Therefore, it was with clear agony that she disclosed how she worried that his aging would result in him no longer being well enough to care for her. She worried about their future and her ability to live at home. She also dealt with the guilt of knowing that if her partner passed away before a certain age she would receive a large insurance payment that would make her living situation much easier. The pain of measuring your partner's life with the insurance payout that would result from his death was heartbreaking to witness.

I highlight Arctic's experience in detail because her life speaks to Barusch's request that we move away from glorifying the resilience of elderly women and instead work towards improving the conditions that force them to be so resourceful in the first place: "Though women are survivors, even they cannot 'live by bread alone' [...] it is 
imperative that we don't just add years to life but also add life to their years" (Curtis, 1995: 179). In this section, I complicate the framing of my research participants as "resilient". The women who participated in this project are indeed strong, resilient individuals with admirable tenacity. They survived a lifetime of hardship with commendable grace; however, as a feminist research project, my work would be incomplete without a critical analysis of the multiple factors that force elderly women to work so hard simply to survive. In this chapter, I use an intersectional analysis to problematize the concept of resilience and, in turn, highlight how resilience is used to promote the neo-liberal individualizing of systemic problems. Using specific recommendations made by the women during their interviews, my goal is to establish a more nuanced, and, in turn, a more complete framework for discussing the lives of economically disadvantaged elderly women in Canada.

There has been a recent surge in academic literature on the issue of resilience (Wild, Wiles and Allen, 2013: 137). Originally used within academia to define the experiences of children raised in difficult circumstances, the term is slowly being used outside of child psychology to define one's ability to bounce back from hardship and adversity, regardless of age or circumstance (Earvolino-Ramirez, 2007). It was clear throughout the interview process with my research participants that I was dealing with a group of highly resourceful and incredibly resilient women. In many cases, they had built up a lifetime's worth of skills and coping mechanisms. As Arctic's story demonstrates, many of the participants were not simply dealing with an aging body. Rather, they were dealing with a multitude of issues ranging from physical illness to family turmoil. For example, having been born in an era where sexism drastically limited women's 
educational and employment opportunities, only three of the seventeen women were able to collect a private pension. With the exception of Arctic's short stint as a high-powered employee in the private sector, the participants who did work outside the home worked in precarious employment such as retail, food preparation, secretarial, homecare and farming. Unstable employment also meant a lack of health benefits, paid vacation and sick days with the most prominent drawback to precarious employment being, of course, low wages. Most of the women worked in a full-time capacity for several years but brought home very little pay. The "recycling poverty" that these women experience highlights a major flaw in simply defining the women as resilient (Perkins, 1993). Defining the participants as resilient rightfully highlights their strength and tenacity; however, it also focuses exclusively on the positive elements of their experience rather than shedding important light on the systemic discrimination that originally forced them into precarious employment.

Resiliency might recognize one's capacity to overcome adversity, but it also implies that the hardships are temporary and that there is an eventual end to the suffering. I disagree. Like Wild, Wiles and Allen, I see "resilience positioned as cumulative, as a process honed by a lifetime of adaptation to hardship" (2013: 144). In the case of the women I interviewed, it was evident that the adversity they faced as economically disadvantaged elderly women did not simply occur once they turned 65 . The women endured a lifetime of misfortune that I see erased by simply positing them as "tough". This is particularly important when you consider that the factors that determine their capacity to cope as an economically disadvantaged elderly women were most often in place before they aged into the category of "elder" (Jensen and McLaughlin, 1997: 467). 
As a feminist researcher, I believe "resilience research must become less concerned with assisting people to 'beat the odds' and more concerned with 'changing the odds' that put people at risk in the first place" (Wild, Wiles and Allen, 147-148). The term resilient is certainly complimentary but when used in isolation it can easily erase the systemic injustices that require such resiliency.

In fact, the implications of describing the participants in this study as resilient are best illustrated through an intersectional analysis. Indeed, Arctic's story highlights very acutely the importance of intersectional analysis. Examining specific elements of her life in isolation fails to recognize the interconnectedness of her experiences of gender, age, ability and class. Arctic was oppressed on the basis of her identity as a woman with a disability but unlike many of the widows I interviewed, Arctic benefited from the support of her spouse. Furthermore, Arctic became disabled in middle age and, as a result, developed coping mechanisms. Lorraine, another participant, also suffered from health problems; however, she had no living partner to assist her. Her illness also came about very suddenly and so she struggled with how to adapt to being bedridden after years of living an active life. Although Arctic and Lorraine's experiences appear quite similar, Arctic benefitted from her marital status in a way that Lorraine did not. Though all 17 participants identified as economically disadvantaged, some were able to continue working as a means of supplementing their income while others had to cease working because of health concerns. Three of the participants resided with partners while the others were either widowed or divorced. All of the women were mothers but three had adult children with cognitive disabilities and one had partial custody of her granddaughter. What these select examples demonstrate is that the participants might be 
resilient overall but that their capacity to cope with particular hardships is significantly dependent on their individual circumstance and identity. We need to critique resilience as a "zero-sum" equation where individuals are either resilient against all hardship or powerless to ever overcoming adversity (Wild, Wiles and Allen, 152-153). Women fail and succeed, often in equal amounts, and our current understanding of resilience as "all or nothing" falls short of capturing those important nuances.

Simply defining economically disadvantaged elderly women as resilient can be used as a justification for denying support. In outlining their critiques of resilience as a concept for critical gerontology, Wild, Wiles and Allen hint at the drawback of simply framing resilient in positive terms. Defining marginalized populations as resourceful and resilient can be enticing to governments and policymakers because "if they can demonstrate that 'some people' cope with adversity and risk successfully, they may be able to imply that everyone "should be able to cope" (154). The desire to recognize the tenacity of oppressed people can easily be used as a means of validating the cutting of social services under the guise that they are no longer needed. This is in line with Canada's increasingly neo-liberal approach to welfare state provisions that increasingly focuses on individualized, and, often privatized, support provision. As Monica Townson notes: "The idea of 'increasing choice' and giving people a 'better range of alternatives' is receiving growing emphasis in policy development, but what does it mean and what could be the likely consequences?" (2006: 7). With the recent scrapping of mandatory retirement in Canada and the raising of the age at which Canadians are eligible for Old Age Security, we have already seen the ways in which the slashing of support services is justified under the guise of "choice" (Government of Canada, 2013). It is important, 
therefore, to recognize the resilience of economically disadvantaged elderly women while also addressing the neo-liberal policies that encourage individualized responses to support. It is imperative that there be a balance between recognizing the strength of these women and maintaining an active critique of the conditions that see them working so hard in the first place.

Arctic's story is a reminder of the complexity of life courses. Although she followed the traditional script of obtaining an education, working a respectable job, getting married and having children, she found herself in her 60s with chronic health problems, an adult son with a cognitive disability, and serious financial hardships. When reflecting on her current situation, Arctic defined it in stark terms: "I will always be just that close from disaster, you know?" For women like Arctic, life is a series of obstacles with little, if any, respite. Seeing the term resilience used in academia to define the lives of groups other than children is encouraging. Recognizing the ways in which populations overcome hardship and continue to live meaningful lives is an important element of social science research. Nonetheless, the term needs continuous refinement and critique. In the case of the research participants in this thesis, they experienced a lifetime of poverty that is not accurately represented by the resilient label. This is not surprising considering the term has rarely been applied to the population in question (Wild, Wiles and Allen, 2011: 153.).

I did not think about framing the lives of my participants within the context of tenacity from the outset and therefore did not explicitly pose such questions. What I did ask, however, was if they had any thoughts on how to improve their situation and the 
lives of future elderly women. If they had the opportunity to meet with government officials and policymakers, what recommendations would they make?

In asking the question to each participant, I was struck by how the women were overwhelmingly self-deprecating in their initial response. Words like "Oh, I don't know" and "Well, I don't really follow politics and that sort of thing" were common. Much like Kestin van den Hoonaard's “Am I doing it right?" research with elderly women, the participants were quick to dismiss their experiences and thoughts as invalid, silly and unimportant. But when I asked a follow-up question, each participant easily went on to describe the thoughts they had. Every participant shared at least one suggestion for how things could be improved for future women like themselves. Although the recommendations varied slightly across all the participants, the most common thread was the importance of social activities. Having conducted my initial interviews during and shortly after Ottawa's longest transit strike, many of the initial responses from participants included discussions of transit and, in particular, the need for the buses to get back on the road. Beyond that, however, the women offered clear recommendations on ways to make social time more accessible. Many of the women spoke at length on the correlation between boredom and loneliness and how it is imperative to keep busy and maintain a busy social calendar. This is not always easy to do, however, particularly if you live alone, have no family members within close proximity or cannot afford to create your own excursions. Three of the participants spoke about their love of small trips to local sights and sounds. Anna-Louise, a rural participant, mentioned that previously her local community centre had organized day trips to museums, public gardens and small venue concerts. She had loved attending them and appreciated that they were always 
reasonably priced and often free. However, with the increase in elderly residents moving out of their homes and into the local retirement facility, there were fewer people to participate in the day trips and the program was cancelled. Margaret, an urban participant, enjoyed day trips as well but found she could no longer attend them with the recent price increase. Although Margaret had family in close proximity, she had found day trips to be an excellent way of breaking up the monotony of everyday life while also being able to meet new people she would not otherwise.

Even when activities are affordable and accessible, they are not always of interest to women. A lot of the services for the elderly are geared towards the deeply aged and fail to recognize the spectrum of abilities and interests that comprise the category "elderly". Arctic spoke of her frustration at being physically disabled like the deeply aged but having the cognition of her 66 year old self: "I've gone to senior gatherings and it's all been women a lot older than me. So, how about recognizing that there are senior citizens that are active and more alert, you know what I mean?" Other women shared a similar sentiment that activities for elderly women rarely expanded beyond lunches at the local church and knitting circles yet the category of "elderly" as defined by most community centres, service providers and policymakers is anyone over the age of 65 . If the average Canadian woman lives well into her 80 s, that is almost a twenty-year difference between herself and a woman recently labeled a senior. There is a need, therefore, for a variety of social activities that reflect the diversity in age groups, interests and personalities of Canada's elders.

Inadequate social services were an important topic in our conversations about recommendations as was having adequate knowledge of existing services. Susanne, an 
urban participant, felt that support services were poorly advertised. She often found herself simply stumbling across information about interesting social programs or community health initiatives. Finding new and creative ways of advertising services was raised by other participants as well who were unsure whether their recommendation was the creation of services or whether the services they were looking for already existed but were simply impossible to locate: "If the services are out there but nobody knows they exist, what good are they?" (Arctic). Susanne suggested that community resources should be promoted to caretakers, particularly adults with elderly parents. Arctic felt that services should be advertised through medical offices as doctors are an important regular point of contact for most elders.

Two participants recommended the reconfiguration of social housing allocations in the city of Ottawa. Margaret and Marie, two urban women, commented on the recent shift in Ottawa Public Housing from seniors' only buildings to mixed housing. Marie felt that the intention behind mixing seniors with the general population was a clear case of theory versus practice. Although the idea of including families and young couples into senior housing complexes is theoretically a great way of diversifying neighborhoods the end result was that many seniors were too afraid to leave their apartments. Loud parties, open drug use and, in some cases, public displays of sex work had many elders isolated in their apartments out of fear: "They have to put up with all this business going on and they're afraid to out of their apartments, especially at night, in the evening. And they're being harassed by drug dealers and everything; they're being harassed by them. If you go to interview some of the old folks in that building, I'm telling you" (Margaret). The call for a return to segregated elderly housing units came from a desire to break the isolation 
of elders. It was also evident from Marie and Margaret's feedback about the policy change that elders had not been adequately consulted prior or since the policy change. They both hypothesized that the rationale for the housing policy change was a means of cutting costs and reducing wait times. Nonetheless, it was evident from their emphatic dislike of the policy that it was not benefitting elders and, in fact, was antithetical to why many chose seniors only housing units. Marie and Margaret's recommendation points to the importance of consulting with elders when making decisions that affect them. It also highlights unintended consequences; in this case, a policy change framed as a means of diversifying neighborhoods and breaking the isolation of elders did exactly the opposite.

As discussed in chapter three, I conducted interviews with women on a range of very personal topics. Interestingly, women were more comfortable sharing family photos with a stranger than discussing their financial situation. The portions of the interviews that dealt specifically with economic hardship were routinely the most difficult. The shame of poverty is profound and, as Barusch's work discusses, women reject stigmatizing labels. Therefore, it was surprising when one of the participants spoke at length about economic policy when discussing recommendations. When I asked AnnaLouise if she had any suggestions for how her situation and the situation of women like her could be improved, she immediately mentioned increasing of Old Age Security. She felt that Old Age Security did not keep up with inflation and the rising cost of living and it was in large part because the people who are affected by those policies are never consulted: "I'd like to see one of those government guys, just for one month, get by on what we get. And then they'd know what it's all about" (Anna-Louise). Her comment summarized the frustration felt by other women who wanted to know why policies are 
made without consultation. Whether it was in relation to the availability of social services or the provision of financial support, there was an underlying dissatisfaction amongst all the women that their voices were not heard. Outlining the lives of economically disadvantaged elderly women and highlighting their resilience in the face of adversity is one way to amplify their voices; however, simply showcasing their resilience does nothing to improve the situation for them or future women like them. One must balance an admiration of resilience with a commitment to changing the circumstances that require so much resolve in the first place. Indeed, Anna-Louise's passionate outcry about her pension struck at the core of my project's intended goal. The women I interviewed felt that their lives were often rendered invisible and my thesis aims to address that invisibility. By focusing on the commonalities between the women, I want to go beyond simply distinguishing among the women and, instead, demonstrate the practical implications of our intersectional lives. The women were divided by geographical differences, employment experiences, marital status, Mother Tongue and a host of other variables. However, they shared a capacity for resilience born from a wealth of social capital and reliance on informal networks for support - emotional and otherwise. All of the women challenged resilience as an individualized concept and demonstrated how one's ability to overcome hardship is linked to community and familial networks. Nevertheless, there were clear limitations to this project that I will outline in the following chapter along with suggestions for future research. 


\section{Chapter Six}

\section{Conclusion}

This thesis examined the daily realities of 17 economically disadvantaged elderly women in rural and urban Ottawa through qualitative interviews. At the outset, my goal was to compare and contrast the experiences of elderly women living in poverty in rural Ottawa versus urban Ottawa. Once the research revealed relatively minor substantive differences between the urban and rural experience, my focus shifted towards examining the tension between documenting resilience while addressing the systems that create the need for such toughness. This thesis argued that elderly women's voices are largely absent in Canada, both from discussions of aging and discussions of women's lives. Economically disadvantaged elderly women are invisible but remain incredibly resilient in the face of significant hardship. Simply labeling them as resilient, however, fails to address the various systems that force them to struggle so hard simply to survive.

The contribution of my research is that it is directed by elderly women's voices. Using feminist research methods, this project was guided significantly by the research participants. This not only challenged the common mistake of speaking about a group rather than with them but also allowed the research to highlight the subtlety and complexity of the women's lives. More than simply documenting some of the stories shared with me by these women, the interview material transformed my thesis from a rural versus urban comparison to a nuanced examination of the ways in which women remain resilient and resourceful in the face of incredible hardship. 
Through reliance on feminist research methods, this project generated rich interview data. The interview process was the focal point of this research and I expended considerable attention to ensuring that the women felt as comfortable as possible speaking to me. The results were lengthy, detailed interviews that in many cases culminated in building a relationship that existed beyond the initial interview. ${ }^{10}$ The women were candid in our conversations and this translated into a wealth of information and multiple hours of rich research data that fell outside the scope of this project but deserves future analysis.

Several of the decisions I made about my research project also revealed the need for further research on Canada's elderly. The decision to interview only Canadian-born women was based on Canada's pension policies that require Canadian residence for a certain number of years in order to be eligible for a public pension. However, the experiences of Canadian elders who are immigrant or refugees form an important but thus far under-researched area, particularly in light of Canada's declining birth rate and aging population.

For the purposes of this study, I defined 'elderly' as 65 and over. During my initial recruiting, I heard from several women in their mid to late 50s who found themselves too ill to work but not old enough to receive a pension. Ageism in the workplace also meant that older workers struggled to find employment, regardless of their skill level or years of experience. Although there is some excellent research on ageism in the workplace and its impacts on women (McMullin and Berger, 2006), there remain many middle-aged women whose experiences are missed by simply examining

\footnotetext{
${ }^{10}$ I remained friends with Lorraine, an urban participant, for a few years after our interview. We remained close friends until her death in 2012. See Appendix B for an excerpt from a letter she wrote me after our initial interview.
} 
the feminization of poverty within the context of single mothers or elderly women. This is another population with whom important research remains to be done.

Finally, the decision to focus on rural versus urban experiences within this project was quickly challenged when the realities faced by both groups were strikingly similar. Nonetheless, I echo Wanless et al.'s (2010) suggestion that future researchers who examine the urban versus rural divide in a qualitative context should focus on where people have lived historically rather than where they currently live. Arctic, a participant living in a rural area, is a perfect example. She lived in an urban area her entire life and had moved just recently to a rural area. She only agreed to do the interview if she fell within the category of "urban" because she had lived in an urban space her whole life.

Resilience as an area of social science research remains largely underdeveloped outside of child studies and child psychology. It is evident from the conclusions drawn in this research project that elderly people offer a wealth of perspectives on resilience as both as a theoretical concept and in terms of applied research. As I argued, defining a demographic of people who have experienced a lifetime of hardship as resilient may be complimentary but offers no reprieve from suffering. In fact, resilience can easily become a trap through which we applaud marginalized groups for their capacity to overcome difficulty while knowingly erasing our complicity in creating the very conditions that force them to be so tenacious. When an entire demographic of women experience similar hardships, it is no longer a matter of individual resiliency but of systemic oppression. We should not focus on "resilience" to the exclusion of critiquing the neo-liberal policies that benefit from said resilience. Analyses of resilience specific to elderly people are few and in a nascent stage (Wild, Wiles and Allen, 141; Hildon, Montgomer, Blane, Wiggins and 
Netuveli, 2009: 37) with research devoted solely to elderly women even rarer. I suggest that research in the area of resilience must include intersectional analyses to focus on explicating the complicated, systemic barriers to women's equality.

My own goal is to expand on this project by researching the practical implications of elderly women's erasure from feminist discourse. As a feminist scholar and activist, I am interested in the impacts of academia's marginalization of elderly women on grassroots organizing. What are the practical implications of erasing elderly women from academic discourse? Does the absence of elderly women's voices in academia translate to an absence of elderly women's voices in the feminist movement writ large? And, if so, how do we work to centre the voices of all women within grassroots feminist organizing in Canada?

A major strength of qualitative research is that it gives research participants the space to give their perspective and flesh out their narrative. By asking participants to define the major concepts under examination, you can ensure that your research is a reflection of the population it is aiming to represent. As Wild, Wiles and Allen pointed out in their analysis of resilience literature, asking the participants to define the terms you are attempting to measure can be a powerful way of ensuring you are working from a common point of understanding between researcher and participants (153). As my thesis demonstrates, creating a relationship with participants in which you entrust them with the expertise to know what is best for them, is an excellent way of soliciting feedback on their needs. In the case of my research, asking the participants to provide me with policy recommendations challenged my perceptions of best practices. I anticipated responses about increasing pensions and, instead, found the majority of participants asking for a 
variety of social activities to stave off boredom. From a policy perspective, in-depth consultation can better ensure that resources are allocated appropriately and best practices are implemented.

Canadians ignore the lives of elderly people at their own peril. As Marilyn, a participant in my research, pointed out in our interview, you can either reject the aging process or die young. And yet, the Canadian perspective on aging, both within academia and popular culture, remains largely simplistic. Labeling elderly women as either resilient or vulnerable fails to recognize the nuance and complexity of the life course. An intersectional analysis is imperative to understanding the life course of women. Elderly women do not exist in a vacuum; their lives are the result of years of difficult experiences that frame their later life.

To conclude, it is my hope that my research provides a launching point for a larger discussion about the importance of using an intersectional analysis to examine elderly women's lives in contemporary Canada. Beyond simple deconstruction, my research makes a case for how a focus on commonalities can help us move from theory to practice. Economically disadvantaged elderly women live complex lives and integrating their voices into academic research will allow researchers to capture those important nuances. The livelihood of our future elderly women depends on it. 


\section{$\underline{\text { References }}$}

Ackerly, Brooke A. Political Theory and Feminist Social Criticism.

New York: Cambridge University Press, 2000.

Alexander, Jo, Debi Berrow, Lisa Domitrovich, Margarita Donnelly and Cheryl McLean. Eds. Women and Aging: An Anthology by Women. Corvallis: Calyx Books, 1986.

Allen, Katherine R. and Alexis J. Walker. "Theorizing about Families and Aging From a Feminist Perspective". Handbook of Theories of Aging. Eds. Bengtson, Vern L., Merril Sliverstein, Norella M. Putney and Daphna Gans. New York: Springer Publishing Company, 2009.

Andrew, Caroline, Pat Armstrong, Hugh Armstrong, Wallace Clement and Leah F. Vosko. Eds. Studies in Political Economy: Developments in Feminism. Toronto: Women's Press, 2003.

Atchley, Robert C. Social Forces and Aging: An Introduction to Social Gerontology._California: Wadsworth Publishing Company, 1991.

Atchley, Robert C. and George Maddox. The Encyclopedia of Aging: A Comprehensive Resource in Gerontology and Geriatrics. $3^{\text {rd }}$ ed. New York: Springer Publishing Company, 2001.

Ash, Irene Borins and Irv Ash. Aging Is Living: Myth-Breaking Stories from LongTerm Care. Toronto: Dunburn, 2009.

Armstrong, Pat, Hugh Armstrong and Krista Scott-Dixon._Critical to care: the invisible women in health services. Toronto: University of Toronto Press, 2008.

Aronson, Jane. "Are we really listening? Beyond the Official Discourse on Needs of Old People”. Canadian Social Work Review. 9:1 (1992): 73-87.

Aronson, Jane. "Old Women and Care: Choice or Compulsion?" Gender, Aging and the State. Peter Leonard and Barbara Nichols. Eds. Montreal: Black Rose Books, 1994.

Aronson, Jane. "Restructuring Older Women's Needs: Care Receiving as a Site of Struggle and Resistance" Restructuring Caring Labour: Discourse, State Practice, and Everyday Life. Sheila M. Neysmith. Ed. Oxford University Press: Toronto, 2000.

Aubrecht, Katie. "The New Vocabulary of Resilience and the Governance of University Student Life". Studies in Social Justice. 6:1 (2012). 67-83.

Barusch, Amanda S. Older Women in Poverty: Private Lives and Public Policies. 
New York: Springer Publishing Company, 1994.

Bezanson, Kate and Meg Luxton. Eds. Social Production: Feminist Political Economy Challenges Neoliberalism. Montreal \& Kingston: McGill-Queen's University Press, 2006.

Biggs, Lesley and Pamela Downe. Eds. Gendered Intersections: An Introduction to Women's and Gender Studies. Winnipeg: Fernwood Publishing, 2005.

Bluhm, Sheila Marie. Aging Beauty: The Adaptive Reconstruction of the Aging Process In Women. Diss. Western Michigan University, 2000.

Bookman, Ann. "Innovative models of aging in place: Transforming our communities for an aging population”. Community, Work \& Family. 11:4 (2008): 419-438.

Brady, Davis and Denise Kall. "Nearly universal, but somewhat distinct: The feminization of poverty in affluent Western democracies, 1969-2000" Social Science Research. 37 (2008): 976-1007.

Broome, Kieran, Linda Worrall, Kryss McKenna and Duncan Boldy. "Priorities for an Age-Friendly Bus System". Canadian Journal on Aging. 29: 3 (2010): 435-444.

Browne, Colette V. Women, Feminism and Aging. New York: Springer Publishing Company, 1998.

Brunie, Aurélie. "Meaningful distinctions within a concept: Relational, collective, and generalized social capital" in Social Science Research. 38 (2009): 251-265.

Bryson, Valerie. Feminist Political Theory: An Introduction. London: Macmillan Press Ltd, 1992.

Calasanti, Toni. "New Directions in Feminist Gerontology: An introduction". Journal of Aging Studies. 18:1 (2004): 1-8.

Calasanti, Toni. "Theorizing Feminist Gerontology, Sexuality, and Beyond: An Intersectional Approach" Handbook of Theories of Aging. Eds. Bengtson, Vern L., Merril Sliverstein, Norella M. Putney and Daphna Gans. New York: Springer Publishing Company, 2009.

Calasanti, Toni M. and Kathleen F. Slevin. Age Matters : Realigning Feminist Thinking. New York: Routledge, 2006.

Calasanti, Toni M and Kathleen F. Slevin Gender, Social Inequalities, and Aging. California: AltaMira Press, 2001.

Calasanti, Toni M., Kathleen F. Slevin and Neal King. "Ageism and feminism: From 
'Et Cetera' to Center". NWSA Journal. 18:1 (2006): 13-30.

Canadian Council on Social Development. "Not Enough: The Meaning and Measurement Of Poverty in Canada". Report of the Canada Council on Social Development National Task Force on the Definition and Measurement of Poverty in Canada. National Library of Canada, 1984.

Casey, Donna. "Long trek to find support at women's drop-in centre". Ottawa Sun. 24 January, 2009: 3.

CBC.ca, "Canadian Women Report Poorer Quality of Life than Men as they Age: StatsCan study involves 7,915 Canadians over age 40". 18 February 2009. $<$ http://www.cbc.ca/health/story/2009/02/18/quality-life.html?ref=rss $>$

Cerwonka, Allaine. "What to make of identity and experience in $21^{\text {st }}$ century feminist research". Theories and Methodologies in Postgraduate Feminist Research._Eds. Rosemarie Buikema, Gabriele Griffin, Nina Lykke. New York: Routledge, 2011. 60-73.

Chappel, Neena, Ellen Gee, Lynn McDonald and Michael Stones. Aging in Contemporary Canada. Toronto: Prentice Hall, 2003.

Charness, Neil and K. Warner Schaie. Impact of Technology on Successful Aging. New York: Springer Publishing Company, 2003.

Christian, Cheryl. "Urban Elderly Women and Fear of Crime: A Sociological Analysis". Diss. University of Manitoba, 2001.

Coleman, James S. "Social Capital in the Creation of Human Capital" The American Journal of Sociology. 94 (1998):95-120.

Collin, Chantal. "Poverty Reduction in Canada: The Federal Role". Political and Social Affairs Division: Library of Parliament, 23 October 2007.

Coward, Raymond T. and John A. Krout. eds. Aging in Rural Settings: Life Circumstances \& Distinctive Features. New York: Springer Publishing Company, 1998.

Craft, Betty J, David R. Johnson and Suzanne R. Ortega. "Rural-Urban Women's Experience of Symptoms of Depression Related to Economic Hardship". Journal of Women \& Aging. 10:3 (1998): 3-18.

Cranswick, Kelly and Derrick Thomas. "Elder Care and the Complexities of Social Networks". Canadian Social Trends: Statistics Canada. Summer. (2005): 10-15.

Cutler, Neal E., Davis W. Gregg, M. and M. Powell Lawton. ed. Aging, Money and 
Life Satisfaction: Aspects of financial gerontology. New York: Springer Publishing, 1992.

Curry, Bill. "CPP reform back on the national agenda". Globe and Mail. 14 December 2012. <http://www.theglobeandmail.com/news/politics/cpp-reform-back-on-thenational-agenda/article6345274/>

Curtis, Z. "Gaining Confidence and Speaking Out". Empowerment in Community Care. Ed. Raymond Jack. London: Chapman and Hall, 1995.

Davis, Christine and Darlene Flett. "Senior Women's Supportive Housing Residence: Phase II - Final Report". Prepared for Cornerstone/Le Pilier. Ottawa: 26 June 2003. 1-28.

Davis, Kathy. "Intersectionality as buzzword: A sociology of science perspective on what makes a feminist theory successful". Feminist Theory._ 9: 1 (2008): 67-85.

Davis, Karen and Paula Grant. “Alone \& Poor”. Generations._14: 3 (1990): 43-48.

De Beauvoir, Simone. La Veillesse. France: Gallimard, 1970.

deGroot-Maggetti, Greg. "A Measure of Poverty in Canada: A guide to the debate about poverty lines". Citizens for Public Justice. March 2002. $<$ http://www.cpj.ca $>$

DeVault, Marjorie L. and Glenda Ross. "Feminist Interviewing: Experience, Talk and Knowledge". Handbook of Feminist Research: Theory and Praxis. ed. Sharlene Nagy Hesse-Biber. California: Sage Publications, 2007: 173-197.

Dodge, Hiroko H. Poverty Transitions Among Elderly Widows._New York: Garland Publishing, Inc., 1996.

Donnelly, Maureen. "The Disparate Impact of Pension Reform on Women." Canadian Journal of Women and the Law. 6: 419 (1993): 419-454.

Donovan, Josephine. Feminist Theory: The Intellectual Traditions. $3^{\text {rd }}$ ed. New York: Continuum International Publishing, 2000.

Dunlop, Donald P. Mandatory Retirement Policy: A Human Rights Dilemma. Ottawa: The Conference Board in Canada, 1979.

Earvolino-Ramirez, Marie. "Resilience: A Concept Analysis". Nursing Forum. 42: 2 (2007): 73-82.

Engels, Benno and Liu Gang-un. "Social exclusion, location and transport disadvantage amongst non-driving senior in a Melbourne municipality, Australia". Journal of Transport Geography. 19 (2011): 984-996. 
Einsenstein, Zillah R. "Developing a Theory of Capitalist Patriarchy and Socialist Feminism". Capitalist Patriarchy and the Case for Socialist Feminism. Monthly Review Press: New York, 1979. 5-55.

Flora, Cornelia Butler, Jan L. Flora with Susan Fey. Rural Communities: Legacy And Change. $2^{\text {nd }}$ ed. Colorado: Westview Press, 2004.

Formosa, Marvin. "Feminism and Critical Educational Gerontology: An Agenda for Good Practice". Ageing International_30: 4 (2005): 396-411.

Garner, J. Dianne. "Feminism and Feminist Gerontology". Journal of Women and Aging. 11 (1999): 3-12.

Garner, J. Dianne. ed. Fundamentals of Feminist Gerontology. New York: Haworth Press Inc, 1999.

Garner, J. Dianne, Susan O. Mercer. ed. Women as they Age. 2nd ed. New York: The Haworth Press, 2001.

Gee, Ellen M and Meredith M. Kimball. Women and Aging._Toronto: Butterworths, 1987.

Government of Canada. "Canada's Economic Action Plan: Eliminating the Mandatory Retirement Age". 1 September 2013. $<\underline{\text { http://actionplan.gc.ca/en/initiative/eliminating-mandatory-retirement-age }>}$

Gibson, Diane. Aged Care: Old Policies, New Problems. Cambridge: Cambridge University Press, 1998.

Green, Bryan S. Gerontology and the Construction of Old Age._New York: Aldine De Gruyter, 1993.

Hancock, Ange-Marie. “When Multiplication Doesn't Equal Quick Addition: Examining Intersectionality as a Research Paradigm". Perspectives on Politics. 5:1 (2007): 63-79.

Hardy, Susan. E, John Concato and Thomas M. Gill. "Resilience of CommunityDwelling Older Person". American Geriatric Society. 52:1 (2004): 257- 262.

Hartmann, Heidi I. "The Unhappy Marriage of Marxism and Feminism: Towards a More Progressive Union". Feminist Theory. Eds. Wendy Kolmar and Frances Bartkowski. Toronto: McGraw Hill, 2005.

Hesse-Biber, Sharlene Nagy. "The practice of feminist in-depth interviewing". 
Feminist Research Practice: A primer. Eds. Sharlene Nagy Hesse-Biber, Patricia Lina Leavy. Thousand Oaks: Sage publications, 2007: 111-148.

Hildon, Zoe, Scott M. Montgomery, David Blane, Richard D. Wiggins and Gopalakrishnan Netuveli. "Examining Resilience of Quality of Life in the Face of Health-Related and Psychosocial Adversity at Older Ages: What is 'Right' About the Way We Age?" The Gerontologist. 50:1 (2009): 26-47.

Howell, Sandra C. "Environment and the Aging Woman: Domains of Choice". Women and the Environment. Eds. Irwin Altman and Arza Churchman. Plenum Press: New York, 1994. 105-130.

Hughes, Bill, Linda McKie, Debra Hopkins and Nick Watson. "Love's Labours Lost? Feminism, the Disabled People's Movement and an Ethic of Care". Sociology. 39: 2 (2005): 259-275.

Jensen, Leif and Diane K. McLaughlin. "The Escape From Poverty Among Rural And Urban Elders" The Gerontologist._37: 4 (1997): 462-468.

Joseph, Jonathan. "Resilience as embedded neoliberalism: a governmentality approach". Resilience. 1:1 (2013): 38-52.

Keating, Norah. Rural Ageing: A good place to grow old? Bristol: Policy Press, 2008.

Kelahear, Ashley. "Government of Canada Highlights Prohibition of Mandatory Retirement". Human Resources and Skills Development Canada. 14 December 2012. $<$ http://www.marketwire.com/press-release/government-ofcanada-highlights-prohibition-of-mandatory-retirement-1737978.htm>

Keller, Heather H, John J.M. Dwyer, Vicki Edwards, Christine Senson, and H. Gayle Edward. "Food Security in Older Adults: Community Service Provider Perceptions of Their Roles". Canadian Journal on Aging. 2:4 (2007): 317-328.

Kelley, Tina. "Knits, Purls, Stump Socks and Outrage". The New York Times. 19 March 2008. <http://cityroom.blogs.nytimes.com/2008/03/19/knits-purls-stumpsocks-and-outrage/>

Kelly, Christine. "Building Bridges with Accessible Care: Disability studies, Feminist Care Scholarship, and Beyond”. Hypatia. 28:4 (2013):784-800.

Kertzer, David I. “Generation as a sociological problem”. Annual review of sociology. 9 (1983): 125-149.

Kestin van den Hoonaard, Deborah. “'Am I doing it right?' Older Widows as interview 
Participants in Qualitative Research". Journal of Aging Studies. 19 (2005): 393-206.

Kilgannon, Gerry. "Women Elders in Action (WE*ACT): Giving Senior Women a Voice in British Columbia". Thirdspace: A journal of feminist theory \& culture. 7:1 (2007): 1-4.

Krekula, Clary. "The Intersection of Age and Gender". Current Sociology. 55: 2 (2007): $155-171$.

Laczko, Frank and Christina R. Victor. ed. Social Policy and Elderly People: The Role Of Community Care. England: Ashgate Publishing, 1992.

Leonard, Peter and Barbara Nichols. Eds. Gender, Aging and the State. Montreal: Black Rose Books, 1994.

Levenson, Alvin J. and Dianna M. Porter. Eds. An Introduction to Gerontology and Geriatrics: A Multi-disciplinary Approach. Springfield: Charles C Thomas, 1984

Lindsay, Collin and Marcia Almey. Women in Canada: A Gender Based Statistical Report. $5^{\text {th }}$ edition. Ottawa: Statistics Canada, 2006.

Little, Margaret Jane Hillyard. "The Limits of Canadian Democracy: The Citizenship Rights Of Poor Women". Canadian Review of Social Policy. 43 (1999): 59-76.

Little, Margaret Janee Hillyard. No Car, No Radio, No Liquor Permit: The moral regulation of single mothers in Ontario, 1920 - 1997. Toronto: Oxford University Press, 1998.

Lochhead, Clarence and Katherine Scott. "The Dynamics of Women's Poverty in Canada". Canada Council on Social Development: Ottawa, March 2000.

Luxton, Meg. "Friends, Neighbours, and Community: A Case Study of the Role of Informal Caregiving in Social Reproduction". Social Reproduction: Feminist Political Economy Challenges Neoliberalism. Eds. Kate Bezanson and Meg Luxton. Montreal: McGill-Queen's University Press, 2006: 263-292.

Mackenzie, Hugh and Richard Shillington. Canada's Quiet Bargain: The Benefits of Public Spending. Canadian Centre for Policy Alternatives. April 2009.

Mancini, Jay A. Eds. Aging Parents and Adult Children. Lexington: Lexington Books, 1989.

Mandell, Nancy. Feminist Issues: Race, Class, and Sexuality. 3rd ed. Toronto: 
Prentice Hall, 2001.

Matthews, Sarah H. The Social World of Old Women: Management of Self-Identity. Beverly Hills: Sage Publications, 1979.

McLaughlin, Janice. Feminist Social and Political Theory: Contemporary Debates and Dialogues. New York: Palgrave Macmillan, 2003.

McClish, Glen and Jacqueline Bacon. "Telling the story her own way: The role of feminist standpoint theory in rhetorical studies". Rhetorical Society Quarterly. 32: 2 (2002): 27-55.

McPherson, Barry D. Aging as a Social Process. Canada: Butterworth \& Co, 1983.

McPherson, Barry D. Aging as a Social Process: An Introduction to Individual and Population Aging. 3rd ed. Toronto: Harcourt Brace \& Company, 1998.

Milan, Anne and Mireille Vézina. "Senior Women”. Statistics Canada. 22 February 2012. $<$ http://www.statcan.gc.ca/pub/89-503-x/2010001/article/11441-eng.htm\#a20>

Milner, Brian and Heather Scoffield. "The growing cost of an aging world". The Globe And Mail. 9 July 2009. <http://www.theglobeandmail.com/report-onbusiness/the-growing-cost-of-an-aging-world/article1211265/>

Morita, Ayako, Takehito Takano, Keiko Nakamura, Masashi Kizuki and Kaoruko Seino. "Contribution of interaction with family, friends and neighbours, and sense of neighbourhood attachment to survival in senior citizens: 5-year follow-up study". Social Science \& Medicine 70 (2010): 543-549

National Advisory Council on Aging. Aging in Poverty in Canada. Minister of Public Works and Government Services Canada, 2005.

Papanek, Hanna. "Family Status Production: The 'Work' And 'Non-Work' of Women" Signs. 4:4 (1979): 775-787.

Perks, Thomas and Michael Haan. "The Dwelling-Type Choices of Older Canadians and Future Housing Demand: An Investigation Using the Aging and Social Support Survey (GSS16)”. Canadian Journal on Aging. 29:3 (2010): 445-463.

Perkins, Kathleen. "Recycling Poverty: From the Workplace to Retirement". Journal of Women \& Aging. 5:11 (1993): 5-23.

Preville, Emmanuel. "Redefining Poverty: The Market Basket Measure." In Brief. Parliamentary Research Branch: Library of Parliament, 29 May 2003.

Priest, Lisa. "Canada's Seniors: The doctor will see you now". The Globe And Mail. 
11 April 2011. $<$ http://www.theglobeandmail.com/news/national/canadas-seniorsthe-doctor-will-see-you-now/article1981281/>

Putman, Robert D. Bowling Alone: The Collapse and Revival of American Community. New York: Simon \& Schuster, 2000.

Ray, Ruth E. "Researching to Transgress: The Need for Critical Feminism in Gerontology". Fundamentals of Feminist Gerontology. Ed. J. Dianne Garner. New York: Haworth Press Inc, 1999.

Ray, Ruth E. "Toward the croning of feminist gerontology". Journal of Aging Studies. 18 (2004): 109-121.

Richmond, Chantelle A.M. "Narratives of social support and health in aboriginal communities". Canadian Journal of Public Health. 98:4 (2007): 347-351.

Rose, H. and E. Bruce 'Mutual Care But Differential Esteem: Caring Between Older Couples'. Connecting Gender and Aging: A Sociological Approach. Eds. S. Arber and N.J. Ginn. Open University Press: Buckingham, 1995.

Rosenthal, Evelyn R. Eds. Women, Aging and Ageism. New York: The Haworth Press, 1990.

Rubinstein, Robert L., Miriam Moss and Morton H. Kleban. Eds. The Many Dimensions Of Aging. New York: Springer Publishing, 2000.

Saucier, Maggi G. "Midlife and Beyond: Issues for Aging Women". Journal of Counseling and Development. 82 Fall (2004): 420-425.

Sayeed, Adil. The 1997 Canada Pension Plan Changes: Implications for Women and Men. Ottawa: Status of Women Canada, 2002.

Scott, Jean Pearson. "Family Relationships of Older, Rural Women: Stability and Change”. Journal of Women._10: 4 (1998): 67-80.

Shenk, Dena. "Subjective Realities of Rural Older Women's Lives: A Case Study". Journal of Women and Aging. 10:4 (1998): 1-24.

Shields, Stephanie A. "Gender: An Intersectional Perspective”. Sex Roles. 59 (2008): 301-311.

Silverman, Philip. "Community Settings" The Elderly and Modern Pioneers. ed. Philip Silverman. Indiana University Press: Indianapolis, 1987.

Simpson, Jeffrey. "Why we need a national seniors' drug plan". The Globe and Mail. 
16 November 2011. $<$ http://www.theglobeandmail.com/commentary/why-weneed-a-national-seniors-drug-plan/article5345823/>

Smith, Geoffrey C. and Gina M. Sylvestre. "Effects of Neighborhood and Individual Change on the Personal Outcomes of Recent Movers to Low-Income Senior Housing". Research on Aging. 30:5 (2008): 592-617.

Smithers, Janice A. Determined Survivors: Community Life among the Urban Elderly. New Jersey: Rutgers University Press, 1985.

Snyder, R. Claire. "Social Capital: The Politics of Race and Gender". Social Capital: Critical Perspectives on Community and "Bowling Alone" Eds. Scott L. McLean, David A. Schultz, and Manfred B Steger. New York: New York University Press, 2002: 167-182.

Staunoes, Dorthe. "Where have all the subjects gone? Bringing together the concepts of intersectionality and subjectification". NORA. 2: 11 (2003): 101-110.

Tam, Pauline. "The rise of the 'wellderly': Growing old at home is the wave of the Future, if the services are there". Ottawa Citizen. 21 April 2009.

$<$ http://www2.canada.com/ottawacitizen/features/longevity/story.html?id=96432f 2e-df20-4b6b-b603-7b2aceea4632>

Thone, Ruth Raymond. Women and Aging: Celebrating Ourselves. New York: The Haworth Press, 1992.

Townson, Monica. A Report Card on Women and Poverty. Ottawa: Canadian Centre for Policy Alternatives, April 2000.

Townson, Monica. Growing Older, Working Longer: The New Face of Retirement. Ottawa: Canadian Centre for Policy Alternatives, 2006.

Townson, Monica. Reducing Poverty among Older Women: The Potential of Retirement Income Policies. Ottawa: Status of Women Canada, 2000.

Tronto, Joan C. Moral Boundaries: A Political Argument for an Ethic of Care. Routledge: New York, 1993.

Turcotte, Martin and Grant Schellenberg. A Portrait of Seniors in Canada. Ottawa: Statistics Canada, 2007.

Unruh, David R. Invisible Lives: Social Worlds of the Aged. Sage Publications: Beverly Hills, 1983.

Varangu, Anne. "Taking a Holistic Approach to Suburbs". Journal of Planning literature. 12: 4 (1998): 469-547. 
Victor, Christina R. Old Age in Modern Society. New York: Croom Helm Inc, 1987.

Vincent, John. Old Age. New York: Routledge, 2003.

Vosko, Leah F. "The Pasts (and Futures) of Feminist Political Economy in Canada: Reviving the Debate" Studies in Political Economy. 68 (2002): 55-84.

Vosko, Leah F. "Workfare Temporaries: Workfare and the Rise of Temporary Employment Relationship in Ontario". Canadian Review of Social Policy. 42 (1998): 55-79.

Walters, William H. "Later-Life Migration in the United States:A Review of Recent Research" Journal of Planning Literature. 17:1 (2002): 37-66.

Wakewich, Pam. "Changing Perceptions of Health and Body Image over the Life Course". ed. Lesley Biggs and Pamela Downe. Gendered Intersections: An Introduction to Women's and Gender Studies. Winnipeg: Fernwood Publishing, 2005: 335-340.

Wanless, Deanna, Barbara A. Mitchell and Andrew V. Wister. "Social Determinants Of Health for Older Women in Canada: Does Rural-Urban Residency Matter?" Canadian Journal on Aging. 29: 2 (2010): 233-247.

Waring, Marilyn. "Unpaid Workers: The Absence of Rights". Canadian Women's Studies. 23: 3-4 (2004): 109-115.

Welsh, Marc. "Resilience and responsibility: governing uncertainty in a complex world". The Geographical Journal. 10:11 (2013): 1-12.

Wenger, G. Clare. "Interviewing older people" Handbook of interview research: Context and method. Eds. Jaber F. Gubrium and James A. Holstein. California: Sage Publishing, 2001: 259-278.

Wershow, Harold J. ed. Controversial Issues in Gerontology. New York: Springer Publishing Company, 1981.

World Health Organization . Global age-friendly cities: A guide. Geneva: World Health Organization. 2007.

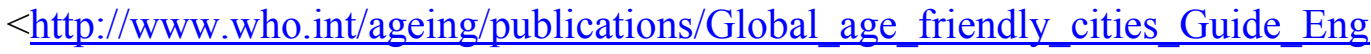
lish.pdf>

Wiegers, Wanda. "The Framing of Poverty as 'Child Poverty' and its Implications for Women”. Status of Women Canada. Ottawa: Government of Canada, 2002.

Wild, Kirsty, Janine L. Wiles and Ruth E.S. Allen. "Resilience: thoughts on the value 
of the concept for critical gerontology". Ageing \& Society. 33 (2013): 137-158.

Woodsworth, David. "A View from the Other Side". Gender, Aging and the State.Eds. Peter Leonard and Barbara Nichols. Montreal: Black Rose Books, 1994.

Zimmer, Zachary, Russell E. Brayley, and Mark. S. Searle. "Whether to Go and Where to Go: Identification of Important Influences on Seniors' Decisions to Travel" Journal of Travel Research. 33.:3 (1995): 3-10.

Zinn, Maxine Baca, Pierrette Hondagneu-Sotelo and Michael A. Messney. Gender through the Prism of Difference. 3rd ed. New York: Oxford University Press, 2005. 


\section{$\underline{\text { Appendix A }}$}

Interview schedule

\section{Interview Number:}

\section{Interview Date:}

Age:

Location:

Mother Tongue:

\section{$\underline{\text { Themes }}$}
1- Location
2- Poverty
3- Relationships
4- Recommendations
5- General

\section{LOCATION}

Where do you live?

Do you live alone? If not, with whom?

How long have you lived in this place? (Home, Apartment)

Do you have any neighbours? How are they?

How long have you lived in this town / city?

What do you like the most / least about this area?

Why did you move here?

Do you have any family here? Friends?

Do you like it here? Dislike it here? Why?

Do you entertain much? Visit others?

How often do you leave the city / town?

\section{POVERTY}

We're currently experiencing some real economic turmoil in this country. How is this affecting you / How will this affect you?

Why do you see yourself as poor? 
Have you always seen yourself this way?

What are your sources of income? What is difficult to access? Was the system difficult / easy to navigate?

Have you always been poor?

When did your income change?

How do you feel at the beginning of the month versus the end of the month?

Describe your work history.

What are you concerned about / not concerned about?

Have you ever felt that you have "gone without" or been denied something?

Are you happy / unhappy with your situation?

Do you know others in your situation?

\section{RELATIONSHIPS}

Are you in contact with other family members? If so, what kind of contact? How often?

Are you in contact with any friends? If so, what kind of contact? How often?

What are those relationships like?

Do you have any pets?

Are you involved in any social committees/organizations? If so, which ones? How often?

What do you feel is your primary relationship?

Do you have any hobbies? If so, which ones? How long? Where did you learn? How often do you partake?

\section{RECOMMENDATIONS}

What do you see as possible solutions to your situation and the situation of people like yourself?

Do you feel that services / resources / programs in your area are adequate? Why?

\section{GENERAL}

Is there any other information you would like to share? 
$\underline{\text { Appendix B }}$

Excerpt from a note that Lorraine wrote to me after our initial interview.

Tom just happy to have. a $1 / 2$ decent place to live. But its taken its toll on me over the years. to people like qu Julie, troat is a very tonight spot in my life t ailing to prep each other, st really helps more tram your le leer Know. just to Know that Hover there t oqured to help me in any way. That is soverif special to me.

111 